\title{
The role of mucus in cell-based models used to screen mucosal drug delivery ${ }^{\text {it }}$
}

\author{
Anna Lechanteur ${ }^{\mathrm{a}, \mathrm{b}, \mathrm{c}, *}$, José das Neves ${ }^{\mathrm{b}, \mathrm{c}, \mathrm{d}}$, Bruno Sarmento ${ }^{\mathrm{b}, \mathrm{c}, \mathrm{d}, *}$ \\ ${ }^{a}$ Marie-Curie COFUND Fellowship, University of Liège, Liège, Belgium \\ b $i 3 S$, Instituto de Investigação e Inovação em Saúde, Universidade do Porto, Porto, Portugal \\ c INEB, Instituto de Engenharia Biomédica, Universidade do Porto, Porto, Portugal \\ d CESPU, Instituto de Investigação e Formação Avançada em Ciências e Tecnologias da Saúde, Gandra, Portugal
}

\section{A R T I C L E I N F O}

\section{Article history:}

Received 16 June 2017

Received in revised form 12 July 2017

Accepted 22 July 2017

Available online $\mathrm{xxx}$

\section{Keywords:}

Mucus

Cell-based models

Mucosal model

Epithelium model

Permeation

Absorption

\begin{abstract}
A B S T R A C T
The increasing interest in developing tools to predict drug absorption through mucosal surfaces is fostering the establishment of epithelial cell-based models. Cell-based in vitro techniques for drug permeability assessment are less laborious, cheaper and address the concerns of using laboratory animals. Simultaneously, in vitro barrier models that thoroughly simulate human epithelia or mucosae may provide useful data to speed up the entrance of new drugs and new drug products into the clinics. Nevertheless, standard cell-based in vitro models that intend to reproduce epithelial surfaces often discard the role of mucus in influencing drug permeation/absorption. Biomimetic models of mucosae in which mucus production has been considered may not be able to fully reproduce the amount and architecture of mucus, resulting in biased characterization of permeability/absorption. In these cases, artificial mucus may be used to supplement cell-based models but still proper identification and quantification are required. In this review, considerations regarding the relevance of mucus in the development of cell-based epithelial and mucosal models mimicking the gastro-intestinal tract, the cervico-vaginal tract and the respiratory tract, and the impact of mucus on the permeability mechanisms are addressed. From simple epithelial monolayers to more complex 3D structures, the impact of the presence of mucus for the extrapolation to the in vivo scenario is critically analyzed. Finally, an overview is provided on several techniques and methods to characterize the mucus layer over cell-based barriers, in order to intimately reproduce human mucosal layer and thereby, improve in vitro/in vivo correlation.
\end{abstract}

\section{Introduction}

Mucosal drug delivery is often foreseen as one of the most convenient, easy and economical ways to deliver drugs to act in the human body. Mucosal membranes are found in the respiratory tract, the eye, the female genital tract and the gastrointestinal tract (GI) tract, which are all exposed to the external environment [1]. Mucosal drug delivery is potentially suitable to allow both targeting topic conditions as Abbreviations: 2D, two-dimension; 3D, three-dimension; ALI, air-liquid culture;
BCS, biopharmaceutics classification system; CV, cervicovaginal; CVM, cervi-
covaginal mucus; DDS, drug delivery systems; ECM, extracellular matrix; FAE,
follicle-associated epithelium; GI, gastrointestinal; iPCS, induced pluripotent stem
cell; IVIVC, in vitro-in vivo correlation; LCC, liquid-covered culture; M cell,
microfold cell; MAP, muco-adhesive particles; MPP, mucus-penetrating parti-
cles; MUC2, mucin-2; $P_{\text {app }}$ apparent permeability; RT, respiratory tract; RT-PCR,
reverse-transcription polymerase chain reaction; SEM, scanning electron micro-
scope; siRNA, small interfering RNA; TEER, Transepithelial electrical resistance;
TEM, transmission electron microscope
? This review is part of the Advanced Drug Delivery Reviews theme issue on
"Technological strategies to overcome mucus barrier in mucosa".
* Corresponding authors at: i3S, Instituto de Investigação e Inovação em Saúde, Rua
Alfredo Allen, 208, $4200-180$ Porto, Portugal.
Email addresses: anna.lechanteur@ulg.ac.be (A. Lechanteur); bruno.sarmento@, ineb.up.pt (B. Sarmento) well as systemic distribution. However, understanding the histology and physiological hurdles of mucosae is essential to allow the effectiveness of free drugs and drug delivery systems (DDS).

The GI tract and the endocervix are composed of a simple layer of columnar epithelial cell, the respiratory tract is covered by a pseudostratified columnar epithelium whereas the vagina, the exocervix and the buccal mucosa are formed by a stratified squamous epithelium [2]. Those mucosal surfaces are more or less constricted in function of their localization, due to different tightness degrees of apical junctions between epithelial cells. Other cell types like ciliated cells [3] or goblet cells [4] may also compose the mucosa and influence drug permeability. After crossing the epithelial layer, drugs diffuse through the extracellular matrix (ECM) at the lamina propria composed of fibrous proteins (e.g. collagen, fibronectin, laminin) and proteoglycans, and bearing immune cells before passing the endothelium and reaching the blood stream [5].

A mucus layer covers all mucosal surfaces and constitutes an important barrier to drug absorption [6]. Mucus is a viscous gel mainly composed of water $(90 \%$ or more) and also of few amounts of salts, carbohydrates, lipids and mucins. These last glycoproteins are the main responsible for the formation of a heterogeneous 3D viscoelastic network [6]. The mucus layer has different thickness and different turnover rates regarding the anatomical localization, physiopathologic status and interactions with the external environment. The complex mucus network constitutes a barrier to bacteria and pathogens 
invasions in order to protect the underlying mucosa but also against drugs or nanoparticles drug carriers transport [7].

For several decades now, various research groups have attempted to mimic in the laboratory different mucosal barriers in order to screen mucosal drug delivery. The most common approach has been the development of cell-based in vitro models, mostly as cell monolayers $[8,9]$. Cellular models are usually constructed by seeding epithelial cells on top of semi-permeable membranes made out of polyester or polycarbonate and mounted in specific cell culture plates, like the popular Transwell@ systems (Corning, NY). The support holding the membrane separates two compartments, the apical and the basolateral, and avoids the wicking and mixing of media between them. Some new and more complex strategies as 3D model, comprising multiple cellular or acellular layers, or "organ-on-a-chip" have also been proposed in order to enhance biorelevance of such in vitro tools [10]. Cell-based in vitro models are generally a compromise between the levels of complexity reflecting the in vivo situation and, what is practicable to reproduce in the laboratory. The elaboration of the mucus layer with right amounts or thickness above the mucosa in a Transwell ${ }^{\circledR}$ system is still a real challenge. Regardless of the mucosal route of administration, it is assumed that the presence of the mucus layer impacts the local action of drugs and their permeability. Many efforts have been done to develop new DDS able to squeeze through the complex mucus network. Thereby, cell-based models mimicking a mucosal surface should include the mucus layer in order to better resemble physiological conditions and allow a more relevant assessment of novel DDS. Indeed, the hurdle posed by mucus is often undervalued in vitro, which could lead to less than optimal drug delivery strategies being evaluated (and failing) in vivo.

We address in this review how the mucus layer is currently considered in the context of in vitro mucosal models and how its presence affects the evaluation and development of new DDS. First, regarding each route of administration, we discuss how the mucus layer is taken into account in the elaboration of cell-based mucosal models. The oral delivery is preferential and still the most widely used, thus, the intestinal barrier is the focus of more detailed discussion. The effect of the mucus layer in in vitro models representing cervico-vaginal, nasal and pulmonary routes is also overviewed. Although attempts have been carried out for the ocular mucosa, these are not yet conclusive and therefore this will not be discussed [11,12]. Some evidences on how the mucus layer may influence results of drug permeability are provided. We then provide useful experimental techniques to identify and quantify mucus layers, as well as future perspectives on how to improve in vitro $3 \mathrm{D}$ mucosal barrier models.

\section{Consideration of mucus layer in cell-based mucosal models}

\subsection{Gastrointestinal tract}

The GI tract stretches from the mouth to the anus and includes the organs necessary to digest food, to process waste and to absorb nutrients, as the stomach, the small and the large intestines. The luminal side of the stomach and the small intestine are fully covered by mucus which maintains a $\mathrm{pH}$ gradient from acid in the lumen to neutral in contact to epithelial cells [13]. As reported by Atuma et al., this mucus barrier is composed of an outer loosely adherent layer and an inner strongly adherent layer. The thickness of the adherent layer depends on the secretion rate and its erosion by enzymes or physical stress [14]. The inner layer is firmly attached to the epithelial cells thanks to glycoproteins and predominantly the mucin-2 (MUC2) interconnected in hexagonal forms that then assembles in parallel sheets $[15,16]$. This viscous and complex mucus network is determinant against pathogens dissemination. Indeed, commensal and environmental microbes are immobilized in mucus via mucin binding which prevents reaching and damaging the underlying epithelium [17]. Johansson et al. have shown that transgenic mice without protein mucin type $2\left(\mathrm{MUC2}^{-/-}\right)$develop rapidly intestinal inflammation and cancers which can partially explain the importance of mucus against pathogens invasion [18]. However, the mucus layer all along the GI tract acts also as a chemical and physical barrier against drug absorption. Its complex composition and organization [19] impairs the transport of several drugs and DDS having completely different physical-chemical properties. Hydrophobic, ionic, enzyme-sensitive or large molecules are typically entrapped or degraded in the mucus network thus reducing their oral availability [20-22]. Since the oral route is the most widely used for the administration of drugs, cell-based mucosal models mimicking the mouth, the stomach and the small intestine have been developed. Some models were proposed to represent the buccal mucosa since this route is quite attractive because of fast drug absorption [23]. However, the presence of the saliva dilutes mucus in the mouth [24] and therefore the importance of mucus as a barrier is likely to be weak. Cell-based models mimicking the buccal mucosa are therefore, not discussed here. In the following, we provide an overview of available models according to anatomic localization, in particular how the mucus barrier is considered and studied.

\subsubsection{Cell-based in vitro models mimicking the gastric mucosa}

The stomach mucosa is in contact with the gastric lumen and is composed of a single-layered columnar epithelium covered by a mucus layer. An acidic gastric juice $(\mathrm{pH} 1.5-3.5)$ is also continuously secreted in the stomach, composed of pepsin, lipase, hydrochloric acid and intrinsic factors [25]. The mucus layer in the stomach prevents the autodigestion of the mucosa and acts as a physical barrier against the acidic gastric fluid. In contrast to the small intestine mucosa, the mucus in the stomach is produced by several types of mucus-secreting cells [26]. In addition, the main function of the stomach is to digest food ingested and transfer it to the small intestine. The absorption rate of nutrients and drugs is low and only desirable for local action of drug which may justify the modest number of cell-based gastric models already developed $[27,28]$.

Human primary gastric epithelial cells have been used to develop cell-based gastric models $[29,30]$. Despite the fact that gastric cell lines are difficult to immortalize, some efforts have been done in that sense because culture maintenance of primary cells is technically difficult. Some cell lines are derived from human gastric carcinomas, namely Hs746t, AGS, NCI-N87 and MKN28, whereas others are derived from normal tissue, such as KATO-III and JOK-1 cell lines $[31,32]$. As an example, the MKN28 cell lines have been used for permeability studies of dextran-FITC $4 \mathrm{kDa}$ in response to aspirin treatment [33]. Although the cohesion of epithelial cells has been validated through tight-junction staining, the presence of the mucus layer has not been taken into account in the study since it is not mucus-producing cell. Another cell line, the NCI-N87, has been established from human gastric carcinoma and seems to be the most attractive until now for developing cell-based models [30,31]. The study of Lemieux et al. showed the integrity of the monolayer formed with this cell line through the quantification of the Transepithelial Electrical Resistance (TEER), which is a quantitative technique to measure the integrity of tight junctions in cell culture models [34]. The production of mucus over the epithelial monolayer has been showed by electronic microscopy [35]. Overall, the development of gastric model is not exhaustive and this observation is explained by the poor amount of drugs absorbed in the stomach.

\subsubsection{Cell-based in vitro models mimicking the small intestine}

The small intestine represents the major site of drug absorption and its epithelium is composed of a single layer of enterocytes char- 
acterized by an apical brush border facing the intestinal lumen. The basolateral side of the epithelium is in contact with the lamina propria containing blood vessels and lymph nodes. The intestinal mucosa is organized in several levels of infolding resulting in an alternation between villi and crypts [36]. In addition to enterocytes present everywhere, goblet cells producing mucus are mainly found on the villi, whereas Paneth cells, which are immune cells, are found in the crypt of the mucosa. Moreover, follicle-associated epithelium (FAE) covering Peyer's patches is also present, as well as microfold cells ( $\mathrm{M}$ cells) that are responsible for the transepithelial transport of pathogens, macromolecules and micro/nanoparticles [37].

Many in vitro intestinal mucosa models have been developed with various complexity. They are mainly used to screen the permeability of drugs or DDS following oral administration. Therefore, the common goal of these models is to closely mimic the architecture and the functional activity of the small intestine, and be reproducible and easily handled in the laboratory in order to decrease the number of in vivo studies and the related ethical considerations. The human colorectal carcinoma cell line Caco-2 is mostly used to study drug absorption through the intestinal mucosa [36]. Caco-2 cells grown on Transwell ${ }^{\circledR}$ systems form polarized monolayers tightly joined with apical microvilli but it is not a mucus-secreting cell lines [38]. By considering an intestinal model only with the Caco-2 cell line, the impact of the mucus layer on drug transport is completely neglected, despite the fact that available evidence points to substantial hindering of the transport of drugs or DDS across intestinal mucus [21,39].

\subsubsection{Intestinal barrier models including the mucus layer}

In order to introduce mucus-producing cells in intestinal models, Lesuffleur et al. established a new cell line termed HT29-MTX which has differentiated goblet cell-like phenotype [40,41]. Walter et al. were the first to co-culture absorptive cells (Caco-2) and mucus-producing cells (HT29-MTX) using starting ratios of Caco-2/HT29-MTX of $75 / 25,50 / 50$ and $25 / 75$ [42]. They showed that the TEER decreased proportionally to the amount of goblet cells present. This observation was expected since the junctions between goblet cells are less tight than those established between enterocytes [4,36]. They selected the ratio of 50/50 and showed higher paracellular permeability of low absorbable hydrophilic drugs (atenolol) on Caco-2/HT29-MTX co-culture as compared to Caco-2 monoculture cell monolayers. Further on, the complete study of Hilgendorf et al. also reported different TEER values in function of initial seeding ratios of Caco-2/ HT29-MTX, namely 90/10, 70/30 and 50/50, as shown in Fig. 1A [43]. Acidic components of mucus were stained with Alcian blue and revealed qualitative difference in the staining depending on the initial seeding density. Moreover, they investigated the impact of these different seeding ratios on drug transport with different permeability characteristics. As previously shown, the permeability of a paracellular marker (mannitol) increased accordingly to the amount of HT29-MTX cells, explained by the decreasing of epithelial resistance. Interestingly, they showed that the permeability of a transcellular marker (antipyrine) was hindered when they used a monoculture of HT29-MTX. They confirmed the hindrance of the drug in the mucus layer since after washing the cell monolayer with HBSS buffer, the permeability became similar to that obtained on the monoculture Caco-2 cell monolayers (Fig. 1B). They highlighted for the first time the importance of considering the mucus layer on an intestinal model permeability in order to screen the permeability of compounds with different physical-chemical properties.

Then, an improvement of the intestinal mucosa models was made by the inclusion of $\mathrm{M}$ cells on the epithelial layer, by culturing the Caco-2 cell monolayer with Raji B cells derived from a human Burkitt's lymphoma. The interaction between enterocytes and the soluble mediators released by the lymphocytes led to the partial change of the phenotype of the Caco- 2 cell population into M-cell like cells [44-46]. This model mimics the FAE which has high transcytosis capacities. The increase of the permeability of cationic polymeric nanoparticles on this FAE model compared to Caco-2 monolayer was observed [47]. Despite the fact that this FAE model can provide a more predictable tool for drugs associated to DDS, the mucus layer was not taken into account. Atuma et al. reported that a loosely adherent mucus layer and a strongly adherent mucus layer of approximately $110 \mu \mathrm{m}$ and $15 \mu \mathrm{m}$, respectively, covered the villi in the whole jejunum [14]. In order to overcome the lack of mucus of the previous, our group investigated the utilization of HT29-MTX cells in the FAE models and proposed a new triple co-culture model. Antunes et al. demonstrated the presence of mucus using Alcian blue staining [4]. Moreover, the impact of the mucus layer was investigated in permeability studies using insulin associated to chitosan-based nanoparticles. Experimental data showed that the permeability of insulin was seven times higher on the triple model as compared to Caco-2/Raji B co-culture cell monolayers. As previously discussed, these values resulted from the lower TEER values for the triple culture, as a consequence of the presence of HT29-MTX cells. Additionally, the presence of mucus can retain the nanoparticles in contact to the mucosa. The nanoparticles were formed with chitosan which is well-described as a mucoadhesive polymer that could delay the diffusion through the mucus. Furthermore, in contact with the epithelium, it has the potential to transiently open epithelial tight junctions [48]. The reliability of the model was also confirmed by comparing permeability value to ex vivo intestinal permeability in rats. In a second study, different initial seeding ratios of Caco-2 and HT29-MTX were tested (90/10, 80/20 and 70/30) and the proportionality between cells were quantified after 21 days in culture [49]. Surprisingly, $\pm 90 \%$ of

\section{A}

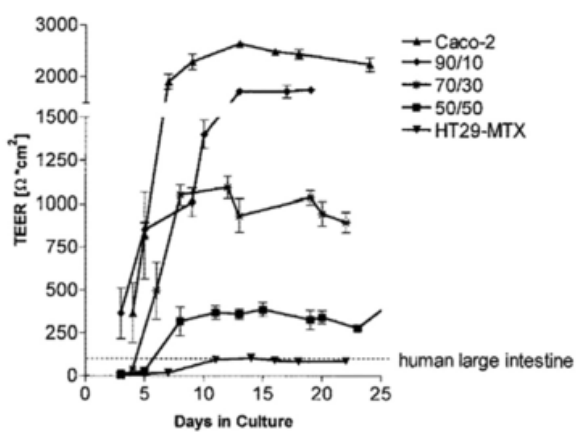

B

\begin{tabular}{|l|c|c|}
\hline \multicolumn{1}{|c|}{ Culture } & Mannitol & Antipyrine \\
\hline Caco-2 & $0.14 \pm 0.01$ & $46.87 \pm 5.50$ \\
$70 / 30$ & $0.54 \pm 0.13$ & \\
$70 / 30$ w/o mucus & $0.80 \pm 0.10$ & \\
50/50 & $1.37 \pm 0.11$ & \\
50/50 w/o mucus & $1.25 \pm 0.14$ & \\
HT29-MTX & $3.18 \pm 0.19$ & $36.37 \pm 1.80$ \\
HT29-MTX w/o mucus & $3.00 \pm 0.26$ & $48.58 \pm 1.96$ \\
\hline
\end{tabular}

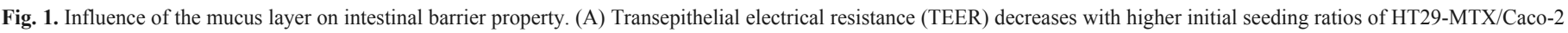
cells. (B) Influence of the mucus layer on intestinal permeability. Reprinted from [43] with permission from Elsevier. 
cells were Caco-2 positive cells regardless of the initial seeding density. Since the physiological percentage of goblet cells into the intestinal mucosa is around 10\% [50], the ratio 90/10 was selected for further experiments. Conversely, Schimpel et al. selected the ratio 70/30 after proving qualitatively that, in this way, complete coverage of the co-culture with mucus was possibly, contrasting with poorer results for lower percentage of HT29-MTX [51].

To sum up, the ability of mucus-producing models to impact permeability of drugs or DDS encapsulating drugs is not conclusive. In fact, it seems that it is more a question of impacting tight junctions following the introduction of goblet cells than the actual mucus barrier effect. This constitutes a major drawback of such models and may be partially solved by the development of improved intestinal barrier models producing mucus.

\subsubsection{New improved intestinal barriers}

New and improved intestinal models have been proposed over the recent years. Other cell types or biomaterials have been integrated into pre-established intestinal models to reproduce as much as possible in vitro the human intestinal morphology and features. The consideration of the mucus layer into these new cellular intestinal models is discussed in this section.

Tridimensional (3D) intestinal models were introduced as alternative to $2 \mathrm{D}$ ones in order to better mimic the functions of living tissues [52]. Indeed, cells within a tissue microenvironment interact differently with each other and with the ECM, thus determining the phenotype and functionality of enterocytes [53]. Li et al. added an ECM composed of rat tail collagen and primary mouse embryonic fibroblasts underneath the co-culture of Caco-2 and HT29-MTX (ratio 90/ 10) cell monolayers [54]. They demonstrated qualitatively and quantitatively that the amount of mucus on this $3 \mathrm{D}$ model was higher as compared to 2D monolayers of Caco-2 cells. However, they did not compare it to the 2D co-culture model and thus the real benefit of the model is delicate to prove. In order to develop a model of the inflamed intestinal mucosa, Leonard et al. seeded Caco-2 cells on the top of a matrix of bovine collagen type 1 containing dendritic cells and macrophages. They showed that the stimulation of Caco- 2 cells with the proinflammatory cytokine IL- $1 \beta$ was accompanied by the production of mucus of $12 \%$ compared to non-stimulated cells [55]. The overproduction of mucus following inflammatory process has been reported for Crohn's disease patients in which hypertrophy of goblet cells occurs [56]. However, the fact that the Caco-2 cell line is able to produce mucus, without the contribution of goblet cells is surprising and we may ask if it is not due to an artifact. In another study,
Pereira et al. used intestinal subepithelial myofibroblasts (CCD18-Co), which have the phenotype of both fibroblasts and smooth muscle cells, embedded in a commercially available protein mixture resembling the basement membrane (Matrigel $\left.{ }^{\circledR}\right)$ and supporting Caco-2 and HT29-MTX (90/10) cells [57]. The TEER values of the $3 \mathrm{D}$ model were lower than the corresponding $2 \mathrm{D}$ model and closely matched typical in vivo transepithelial resistance [43]. However, the impact of the $3 \mathrm{D}$ conformation on the production of mucus was not investigated in a different way than by the evaluation of TEER. Regarding those information, 3D cellular intestinal models have been developed to improve the prediction of drug permeability but have not shown an improvement of mucus production yet.

Another type of model involves the creation of a 3D small intestine with artificial topography through the utilization of biomaterials. This consists of building 3D scaffolds to reproduce the same size and shape of intestinal villi in order to provide a more physiological relevant microenvironment. For example, Lee et al. have reconstructed the shape of villi with a PLGA scaffold manufactured by 3D printing [58]. Other biomaterials such as poly(dimethylsiloxane) coated with fibronectin [59], collagen coated with fibronectin [60] or collagen/polyethylene-glycol hydrogel $[61,62]$ have also been used in order to serve as substrate for obtaining Caco-2 cell monolayers. Indeed, Caco-2 cells can effectively grow and differentiate on these intestinal crypt-like topographies but the importance of the mucus layer was not considered at that time. In 2014, Costello et al. investigated in details the production of mucus by Caco-2 and HT29-MTX (ratio 66/33) cell monolayers on top of a 3D PLGA scaffold [63]. These researchers detailed by confocal microscopy on the structure of the cell monolayer, including the presence of a mucus layer (Fig. 2). Moreover, after 21 days, the amount of mucus production by HT29-MTX growing on the 3D PLGA scaffold was higher than that observed for the 2D-co-culture on Transwell ${ }^{\circledR}$ system. They also showed that the mucus production in 2D decreased between 7 and 21 days which was explained by a rapid growth of the HT29-MTX cells on the Transwell ${ }^{\circledR}$ inserts that led to a more rapid decline and cessation of mucus production. The TEER values were two times higher for the 2D model, which could also prove the lower production of mucus since it modifies the epithelial integrity due to less tight junctions. Afterwards, they considered the utilization of this scaffold to establish microbial niches along the crypt-villus axis [64].

Chen et al. have also shown the positive impact of mimicking the villi conformation of the intestine on mucus production. They seeded Caco-2 cells and HT29-MTX cells (ratio 66/33) on a 3D silk scaffold encompassing primary human intestinal myofibroblasts (H-InMy-
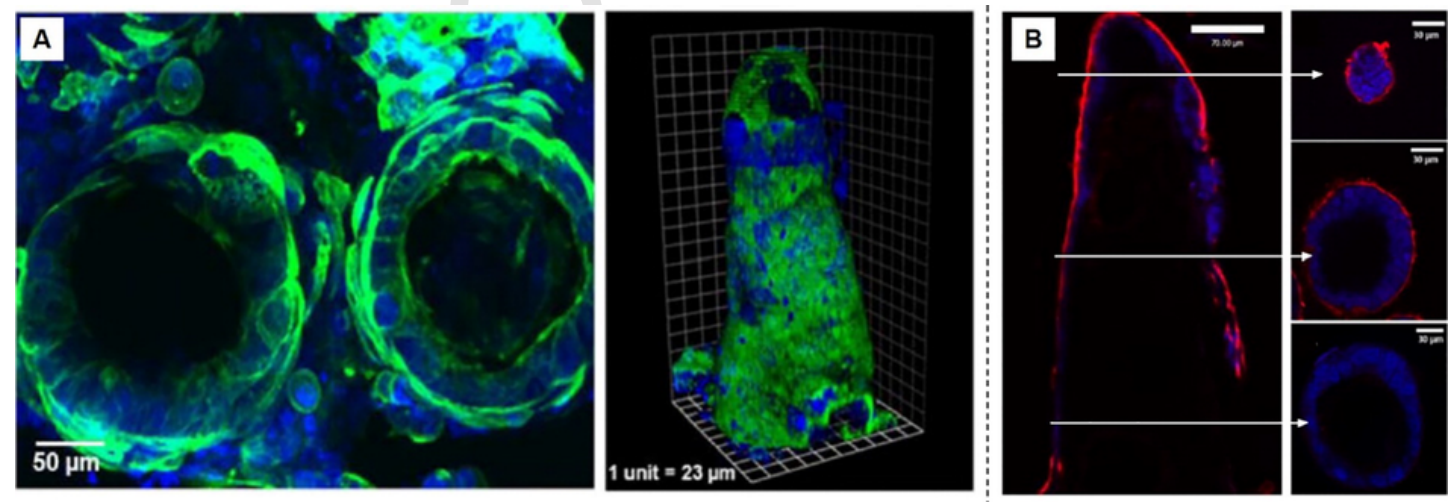

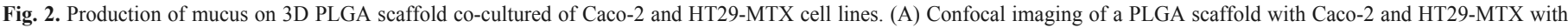

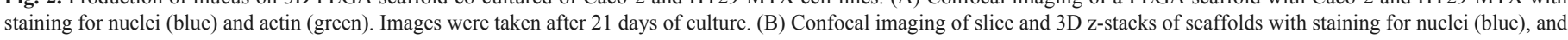

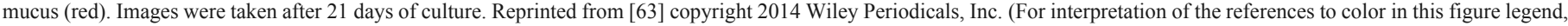
the reader is referred to the web version of this article.) 
oFibs) and showed the increased production of mucus [65]. By including an ECM into their model, they added another important parameter of the intestinal mucosa. Whereas these two studies showed interesting results in terms of mucus production, it seems essential to study these findings alongside permeability studies of several drugs.

Isolated primary intestinal cells and induced pluripotent stem cells (iPCS) $[66,67]$ have also been considered to establish intestinal models in vitro. Those cells could offer an alternative source of human intestinal cells, but culture conditions are tricky and actually difficult to envisage for robust in vitro intestinal models. Finally, a new trend intends to reproduce the entire gut-blood barrier by introducing the endothelium layer within in vitro models $[68,69]$. Until now, no studies have investigated the impact of the presence of endothelial cells on the production of mucus.

Through this section, we highlight the extent of the small intestine models developed and how the production of mucus was considered (Table 1). The optimal initial seeding density of different cell types is not yet well-established and its impact on drug permeability neither. The importance of considering the mucus layer on cell-based intestinal models is dramatically influenced by the goals of the performed study. Indeed, the intestinal permeability of some drugs, either free or associated to DDS, is not described as being hindered by the mucus layer. In this case, the utilization of an intestinal model containing a well-defined and well-characterized mucus layer is probably not crucial, although the presence of goblet-cells influences the transepithelial resistance. On the other hand, many other sensitive drugs are degraded (e.g. proteins) or entrapped (e.g. lipophilic drug) in the intestinal lumen due to numerous interactions with mucus components. Active researches are now focusing on the development of muco-adhesive particles (MAP) or mucus-penetrating particles (MPP) allowing the efficient delivery of drugs which cannot effectively reach the epithelium mucosa alone. MPP diffuse better than conventional nanoparticles within the mucus matrix and reach faster the epithelial layer whereas MAP adhere to the mucus layer and consequently increase the residence time and contact intimacy with the mucosa $[6,115]$. In this case, the utilization of a cellular model comprising a mucus layer with the optimal quantity, thickness and composition will dramatically determine the issue of these experiments. In order to develop a model allowing the screening of multiple drug delivery, we may suggest to always use a mucus-secreting cell model.
Importantly, two characteristics of the mucus in the GI tract has never been emphasized. The formation of the double-layered mucus of which the outer layer is loosely adherent and the inner layer is strongly attached to the mucosa remains a real challenge [65]. The utilization of cell-based model in 2D and the lack of dynamic culture environment could explain this observation. The second shortcoming of the mucus produced by cell-based model is its structure and composition [70]. Some differences between mucus from cell culture and native mucus have been highlighted as the mesh spacing [71] or the mucin expression pattern. For instance, the HT29 cell line mostly secrete MUC5AC instead of MUC2 which is the dominant secreted mucin in the small intestine [41]. These observations can be explained by the fact that most cell lines used to construct cell-based models come from tumors [72]. Therefore, the mucin protein expression can be altered in cancer cell and consequently affect the mucus produced on the top of these in vitro models.

\subsection{Respiratory tract}

The respiratory tract extends from the nasal cavity to the pulmonary alveoli where exchanges between air and blood occur. The respiratory tract is divided into two segments: the upper composed of the nasal cavity, pharynx, and larynx, and the lower RT, which comprises the trachea, bronchi and lungs. The respiratory epithelium is formed by a ciliated pseudostratified columnar epithelium where epithelial, ciliated and goblet-cells coexist. Moreover, mucus-producing glands are also present and together with the previous forms the well-known mucociliary escalator that induces a rapid clearance of inhaled particles. As in the case of other routes of administration, the role of mucus is to prevent some infections of the underlying mucosa. Cell-based in vitro models have been developed for the nasal and the bronchial mucosa, as well as the alveoli portion mimicking the air-blood barrier. Indeed, those sections are responsible for drug absorption and thereby, cell-based models are useful to develop new inhaled drugs or DDS [77]. This chapter is focused on the consideration of the mucus layer in in vitro cell-based models mimicking the RT.

\subsubsection{Nasal mucosa models}

The nasal route of drug delivery is regarded as having different and interesting advantages. The nasal mucosa possesses a high vascularization which typically induces rapid and direct blood transporta-

Table 1

Comparison of cell-based intestinal models and their consideration of mucus layer.

\begin{tabular}{|c|c|c|c|c|c|}
\hline & Cell lines & Ratio Caco-2/HT29-MTX & Consideration & f mucus & Ref \\
\hline \multicolumn{2}{|l|}{ Co-culture models } & & Qualitatively & Quantitatively & \\
\hline & Caco-2 + HT29-MTX & $75 / 25 ; 50 / 50 ; 25 / 50$ & $\mathrm{Y}$ & $\mathrm{Y}$ & {$[42]$} \\
\hline & Caco-2 + HT29-MTX & $90 / 10 ; 70 / 30 ; 50 / 50$ & $\mathrm{Y}$ & Y & {$[43]$} \\
\hline & Caco-2 + HT29-MTX & $33 / 66$ & $\mathrm{Y}$ & $\mathrm{N}$ & [73] \\
\hline \multicolumn{6}{|l|}{ Triple models } \\
\hline & Caco-2 + Mice lymphocytes & - & $\mathrm{N}$ & $\mathrm{N}$ & {$[44]$} \\
\hline & Caco-2 + Raji B & - & $\mathrm{N}$ & $\mathrm{N}$ & {$[45,46]$} \\
\hline & Caco-2 + HT29-MTX + Raji B & $90 / 10$ & $\mathrm{Y}$ & $\mathrm{N}$ & [4] \\
\hline & Caco-2 + HT29-MTX + Raji B & $90 / 10 ; 80 / 20 ; 70 / 30$ & $\mathrm{Y}$ & $\mathrm{N}$ & [74] \\
\hline & Caco-2 clone + HT29-MTX + Raji B & $90 / 10 ; 80 / 20 ; 70 / 30 ; 60 / 40 ; 50 / 50 ; 40 / 60 ; 30 / 70 ; 20 / 80 ; 10 / 90$ & $\mathrm{Y}$ & $\mathrm{N}$ & {$[51]$} \\
\hline & Caco-2 + HT29-MTX + Raji B & $90 / 10$ & $\mathrm{Y}$ & $\mathrm{N}$ & {$[75]$} \\
\hline \multicolumn{6}{|l|}{ ECM models } \\
\hline & $\begin{array}{l}\text { Caco-2 Clone HTB37 } \\
+ \text { HT29-MTX + MEFs }\end{array}$ & $90 / 10$ & $\mathrm{Y}$ & Y & {$[54]$} \\
\hline & Caco-2 clone $\mathrm{C} 2 \mathrm{Bbe} 1$ & - & $\mathrm{Y}$ & Y & {$[55]$} \\
\hline & $\begin{array}{l}\text { Caco-2 } \\
+ \text { HT29-MTX + CCD18-Co }\end{array}$ & $90 / 10$ & Y & $\mathrm{N}$ & {$[57]$} \\
\hline \multicolumn{6}{|c|}{ Artificial topography models } \\
\hline & Caco-2 & - & $\mathrm{N}$ & $\mathrm{N}$ & {$[59,61,62,76]$} \\
\hline & Caco-2 + HT29-MTX & $66 / 33$ & $\mathrm{Y}$ & $\mathrm{Y}$ & {$[63,64]$} \\
\hline & Caco-2 + HT29-MTX + H-InMyoFibs & $66 / 33$ & $\mathrm{Y}$ & $\mathrm{Y}$ & {$[65]$} \\
\hline
\end{tabular}


tion of permeated drugs. This route of administration is now mainly investigated to target the central nervous systems by crossing the blood-brain barrier or for the systemic administration of peptides [78]. However, quick mucociliary clearance $(6 \mathrm{~mm} / \mathrm{min})$ and the presence of enzymes can impair drug permeability as already reviewed by Beule et al. [3]. The thickness of the mucus layer in the nasal cavity is low $(10-15 \mu \mathrm{m})$ and divided into the lower thick liquid phase and the upper gel phase [79]. The nasal mucus thickness is the lowest all over the body but at the same time, the mucociliary clearance induces the fastest turnover. Therefore, we can wonder how the mucus layer has to be considered in nasal cell-based models.

Different primary cells have been isolated from human nasal epithelial tissues [80]. Kissel et al. developed a primary cell line [81] and used it to test the permeability of three peptides [82]. However, they did not demonstrate the production of the mucus layer above the monolayer and therefore its impact on nasal drug permeability was not addressed. Furthermore, the culture of primary cells from animal tissues is difficult and rather heterogeneous. The culture of human cells lines is more convenient and the population considered more homogeneous. However, the most well-known nasal cell line, RPMI 2650 cells, is not ciliated not producing mucus [83].

Regarding those information, the effect of the mucus layers on nasal drug permeability is now mainly studied thanks to human bronchial cell lines (discussed in the next section). These cell lines are also used to mimic the bronchi barrier since nasal and respiratory epithelium present similar features.

\subsubsection{Bronchial mucosa models}

The administration of multiple drugs through the pulmonary route has also been considered as a noninvasive route of administration. The inhalation of peptide or gene, for instance, is a promising alternative to systemic administration since the pulmonary mucosa is highly vascularized and the absorption area is high [84]. After passing the trachea, drugs or DDS reach the bronchial tree depending on its hydrodynamic diameter. Two types of cell-based models have been proposed according to localization and deposition of drug in the lung. Therefore, the development of epithelial cell layers mimicking the epithelium of the airway/bronchial and of alveolar regions of the lung has been pursued. The upper (including the nasal mucosa) and lower airway epithelia have close histological features, being lined by a mu- cus layer of around $55 \mu \mathrm{m}$ [85]. Conversely, the mucus layer in the alveolar region, where gas exchanges occur, is negligible and thereby, the inclusion of goblet cells or other sources of mucus is not considered in such cell-based models developed so far.

Commercial bronchi epithelial models with different levels of differentiation were developed by MatTek Corp., as the EpiAirway ${ }^{\mathrm{TM}}$ model series. These models produce mucus but are composed of primary cells [86]. Considering drawbacks of using in vitro models made with primary cells, they are not considered in the present discussion. Furthermore, different previous reviews have described in detail all bronchial or alveolar cell lines used to develop lung cellular models [87-89], whereas here, we selected only bronchial cell lines producing-mucus and forming tight-junctions, in particular the human airway epithelial cell line Calu-3.

Contrasting with cell-based intestinal models using the Transwell ${ }^{\circledR}$ system in a "liquid-covered culture" (LCC) configuration, bronchi models can also be set up in an "air-liquid interface" (ALI). A schematic picture of the two methods is represented in Fig. 3A.

Because of these two possible configurations, a wide range of variations can be found among studies reported in the literature in terms of barrier integrity and, more important here, of mucus production. For example, Fiegel et al. highlighted the difference of barrier properties between Calu-3 cells seeded in LCC or in ALI configuration [90]. After the incubation of PLGA microparticles loaded with fluorescein sodium (paracellular transport marker), they found that the TEER was lower and thus the permeability was higher for the model in LCC configuration. Moreover, they showed by acidic glycoproteins staining that the model in ALI configuration exhibited a uniform mucus layer, contrasting with its absence in the LCC configuration. Thereby, the mucus layer on ALI model can protect the underlined epithelium whereas its absence may cause short-term damage, leading to the increased flux of the paracellular marker in the LCC configuration. The addition of medium into the apical side can dilute produced mucus and influence the overall barrier properties. These observations were also validated by Grainger et al. by using Alcian Blue staining [91]. Recently, it was shown by Kreft et al. that after 3 weeks in culture, Calu-3 maintained in ALI conditions formed a differentiated pseudostratifed epithelium with positive cell staining with Alcian Blue [92]. However, cells maintained in LLC configura-

Liquid-cover culture (LCC)

Air-liquid interface (ALI)
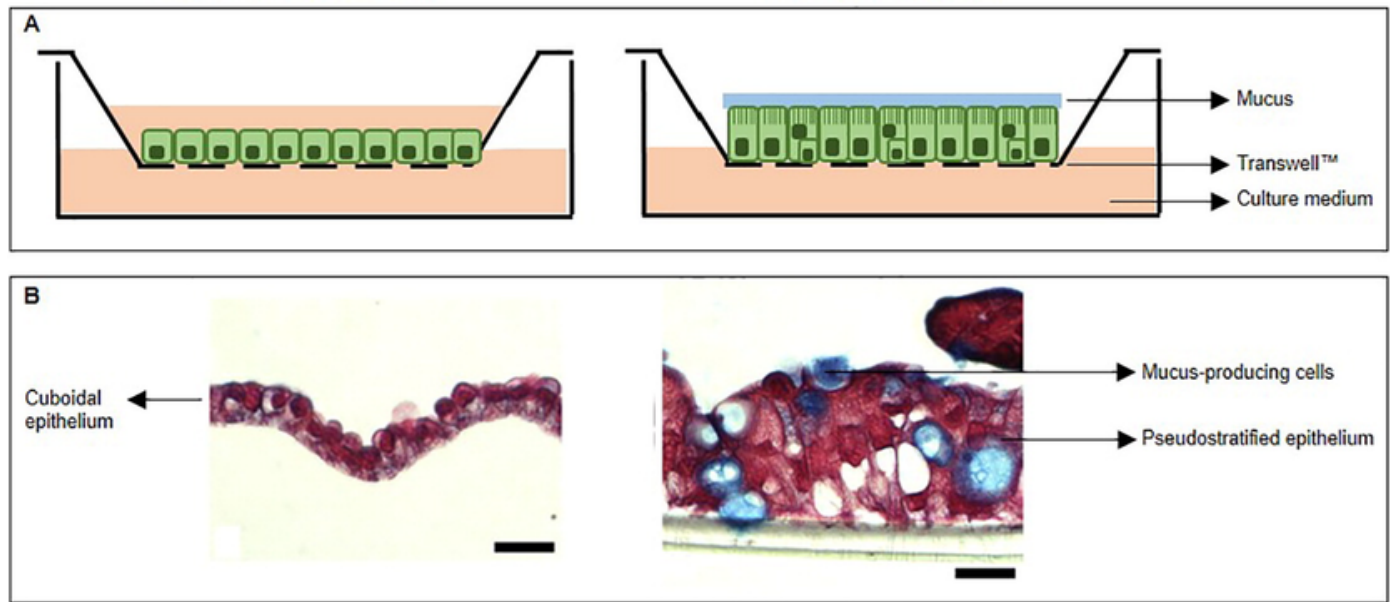

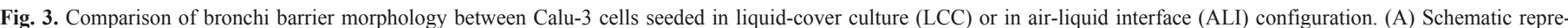

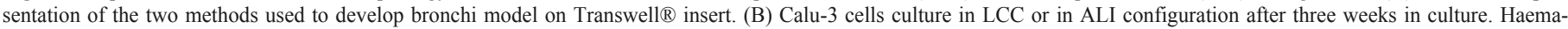

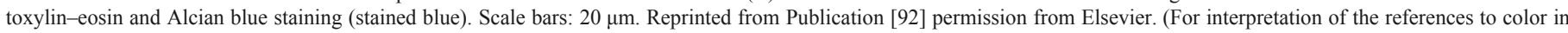
this figure legend, the reader is referred to the web version of this article.) 
tion formed only a simple cuboidal epithelium without mucus layer (Fig. 3B).

Overall, the development of lung model with Calu-3 cells in ALI configuration seems more appropriate to resemble the native bronchiolar epithelium producing a mucus layer. The presence of the mucus gel on bronchi cell models is crucial since many respiratory diseases as asthma, chronic obstructive pulmonary diseases or cystic fibrosis are characterized by the overexpression of mucus and by the obstruction of mucus glands [93]. Despite these evidences, some authors still use the LCC configuration to test the permeability of DDS.

Some attempts to improve the classical monoculture model has be done using a 3D model [94,95] or the "organ-on-a-chip" techniques [96]. These models were well-characterized in terms of mucus production with different methods described in Section 5. However, until now, all of them were done with primary human cells and the impact of mucus layer on drugs permeability was not investigated.

\subsection{Cervico-vaginal tract}

The cervico-vaginal (CV) tract is divided in the vagina and the ectocervix which are composed of a stratified squamous epithelia and, the endocervix and the body of the uterus composed of a single-layered columnar epithelia. The two types of epithelia are linked by the squamocolumnar junction or transformation zone. The profuse vascular irrigation, the low enzymatic activity, the good mucosal permeability for some compounds (e.g. sex hormones) and the fact that the vaginal administration avoids the hepatic first-pass clearance make of this route an attractive alternative for the delivery of proteins, peptides, small interfering RNA (siRNA) and plasmid DNA [85,97-99]. The vaginal administration of several drugs is also considered for the prophylaxis of bacterial or viral infections and for the treatment of multiple infections and cancer as well. Contrasting with the GI tract, the human vaginal mucosa does not contain mucus-producing goblet cells $[100,101]$. The vaginal fluid results from the mixture of endometrial fluid, cervical mucus, tissue transudate, vestibular glands secretions, immune and epithelial cells, and residues of urine [102]. This fluid is called cervico-vaginal mucus (CVM) and is mainly composed of water, mucin fibers, various electrolytes, bacteria and lipids, as previously reported for the intestinal mucus [103]. Consequently, the $\mathrm{CV}$ tract is underlying by a discontinuous thin layer of fluid (average thickness around $50 \mu \mathrm{m}$ [104]) of a maximal volume of around $1-2 \mathrm{~mL}$ [100] and a $\mathrm{pH}$ in the range of 3.5-4.5 [105]. However, the volume, composition, $\mathrm{pH}$ and viscosity change according the age, menstrual cycle and sexual intercourse [106]. These modifications represent a unique behavior and must be taken into account when considering vaginal drug administration. Despite this, the CV tract is recognized as an interesting route for the administration of various drug since local and systemic drug delivery can potentially be achieved $[107,108]$. Human ectocervical epithelial cells $[109,110]$ or immortalized humans genital cells (Caski, SiHa, HEC-1A) [111-114] have been considered to develop vaginal cell-based epithelial models and used to test the permeability of drugs. None of these cells are mucus-producing cells and therefore, the impact of the mucus layer is not taken into account. Different commercial models are also available as the EpiVaginal ${ }^{\mathrm{TM}}$ model series (MatTek Corp.), which reconstruct the multilayered structure of the epithelium and have been used for safety and permeability studies $[115,116]$. However, this model does not include the mucus layer neither.

Overall, the impact of the mucus layer on the penetration of drugs associated to DDS, through the $\mathrm{CV}$ tract can be studied in two different ways. First, as previously reviewed by Griessinger et al., multiple techniques have been developed to study the mucus permeation or the mucus diffusion of DDS [117]. Transwell diffusion system (without cell seeding) [118] and multiple particle tracking [119] are mainly used. The second strategy is to add native or simulated vaginal fluid above the reconstructed multiplayer epithelium. This technique will be explained more deeply in Section 3. Therefore, vaginal permeability studies using current cell-based models may be generally considered as incomplete and, thus, require to be performed in combination with other techniques.

Throughout this whole section, we showed that the impact of the mucus layer on cell-based models is sometimes neglected. In order to prove that the development of MAP or MPP brings a real interest in drug permeability through mucosa, the right in vitro model producing mucus has to be used. As reviewed by Araújo et al. many surface functionalization strategies have been proposed to enhance mucosal drug absorption [120]. However, in vitro barrier models used to screen the transport and the enhancement of permeability with the utilization of MPP or MAP are not always relevant and the impact of the mucus layer is too often neglected. These in vitro tools are useful to speed up the pharmaceutical development of drugs but the more appropriated model has to be selected to really improve the in vitro-in vivo correlation (IVIVC).

\section{Supplementation of cell-based mucosal models with artificial mucus}

Beyond the typical approach of including mucin-producing cells in cell-based models, as described above, some authors have further considered adding mucus to pre-formed cell membrane models. Human native mucus is not easy to obtain and inter-individual variations may introduce significant bias to the outcome of performed experiments. Fluids from animal sources can be alternatively considered but, those of human origin, also present high variability regarding their composition and 3D architecture that influence the biophysical features of mucus, namely its barrier properties [7,121,122]. Moreover, toxicity issues to cell cultures have been raised for fluids collected from animals [123]. Thus, mucus-like fluids are mostly considered for such purpose. Different recipes have been proposed in the literature and those containing or modified with commercially available mucins may be of particular interest [103,119,123-127].

There are some advantages in using artificial mucus. For instance, this allows overcoming the lack of mucus-producing ability of most of the common cell-based membrane models used in drug delivery studies [8]. Also, the composition of artificial mucosal fluids can be clearly defined allowing to reduce bias induced by variable qualitative and quantitative production of mucin-producing cells that are highly dependent on stimuli during handling $[128,129]$. Indeed, it is likely that mucus produced by goblet cell in culture do not actually mimic native mucus [130]. Also, the amount of mucus originated by using these mucin-producing cells is meager and typically originates discontinuous layers of reduced thickness over cell membranes that may not be fully representative of the in vivo situation [74]. Using external sources of mucus may further abbreviate changes induced to cell monolayer tightness by the incorporation of cell types presenting different abilities to establish intercellular interactions. For example, our group has recently shown that various drugs present increased permeability across Caco-2/HT29-MTX co-culture cell monolayers as compared to Caco-2 cell monolayers [131]. These observations have been justified with the reduced ability of mucus-producing cells to establish tight-junctions thus leading to a leaky cell monolayer. Indeed, the ability of mucus to act as a barrier was likely outshined by the enhanced drug permeation across cell monolayer.

Nevertheless, the use of simulated fluids also presents several caveats. First off, such practice comprises a clear exaggeration of the natural mucus barriers present in vivo. Artificial mucus is typically added on top of cell monolayer models grown on Transwell ${ }^{\circledR}$ (or similar) systems in order to fill the apical side. This creates a mucus- 
like layer with several millimeters in thickness, contrasting with what happens at mucosae (from a few to $<0.5 \mathrm{~mm}$, depending mainly on anatomical sites and physiological conditions [132]). Another issue has to deal with the properties of used mucins. Commercial mucins are typically available from various sources and in different types but substantial processing during purification is known to significantly alter the properties of native glycoproteins [133-135]. This may lead to modified behavior and performance, namely of barrier properties, of reconstituted artificial mucus. Indeed, mucus surrogates are not able to reproduce in detail the absolute biophysical properties of native fluids, although parallel behavior has been reported, namely for drug and particle diffusion in native and surrogate pig intestinal mucus [136,137]. Another issue of using commercial mucins relates to the possible onset of cytotoxicity, namely due to the undesirable presence of compounds used or originated during processing [138]. This could compromise the functionality of cell membranes and thus impact on the outcome of assays. Using optimized processing for obtaining more native-like mucins could help circumvent discussed limitation but inter-laboratory variations and different sources of crude mucus are hard hurdles to overcome. It should be highlighted that other components of artificial mucus may also induce toxicity and their effect on cell viability needs to be assessed.

Different studies using surrogate mucosal fluids, mainly for including into pre-established cell monolayer models of permeability, have been described in the literature. These have been shown useful in demonstrating the potential of mucus as a barrier to drugs and their carriers. For example, Teubl et al. proposed an interesting in vitro setting based on the addition of an external mucus-like barrier to human buccal epithelial TR 146 cell monolayers in order to study the transport of nanoparticles [139]. The mucus layer was obtained by pre-preparing films of mucin and glycerol with approximately $71 \mathrm{mg} /$ $\mathrm{cm}^{2}$ and $14 \mathrm{mg} / \mathrm{cm}^{2}$, respectively, which were placed on top of TR 146 cell monolayers for $24 \mathrm{~h}$ before qualitative nanoparticle transport ex- periments. Commercial pig gastric mucin was used as it presented close chemical and morphological features to mucins obtained from human saliva and reduced cytotoxicity (as compared to mucin from bovine submaxillary glands). Microscopy studies were able to show that an adherent layer of mucin was present on top of cell monolayers but no data was provided regarding its thickness. The proposed model was successfully used to demonstrate different behaviors of $200 \mathrm{~nm}$ nanoparticles bearing various surface properties and, in particular, correlated well with ex vivo experiments performed using pig buccal mucosa (Fig. 4).

In another report, Boegh et al. developed artificial intestinal mucus by comparing its rheological features with native pig intestinal mucus [123]. The simulated fluid was also optimized to display low cytotoxicity to Caco-2 cells and negligibly affect TEER of monolayers of these last cells. The final composition was isoosmolal, with $\mathrm{pH} 7.4$, and comprised 5\% (w/v) pig gastric mucin type II, $0.9 \%(w /$ v) Carbopol ${ }^{\circledR} 974 \mathrm{P} \mathrm{NF}, 3.1 \%(w / v)$ bovine serum albumin, $0.11 \%(w /$ v) linoleic acid, $0.36 \%(w / v)$ cholesterol, $0.18 \%(w / v)$ phosphatidylcholine and $0.163 \%(w / w)$ polysorbate 80 in HEPES buffer $(10 \mathrm{mM}$ HEPES, $1.3 \mathrm{mM}$ calcium chloride, $1.0 \mathrm{mM}$ magnesium sulfate, $137 \mathrm{mM}$ sodium chloride). The artificial mucus was added on top of Caco-2 monolayers grown in Transwell® systems and permeability experiments were conducted using hydrophilic (mannitol, FD4, FD10 and fluorescein isothiocyanate-bovine serum albumin) and hydrophobic (testosterone) compounds. Reduction in apparent permeability $\left(P_{\text {app }}\right)$ values varied between 1.2 for mannitol and 6.8 for testosterone.

CVM plays an important role in mucosal physiology and its importance in HIV dynamics leading to transmission is considered of relevance [140,141]. Our group is actively engaged in the development of vaginal microbicides, i.e. products able to circumvent local male-to-female viral transmission events upon sexual intercourse, namely those based on nanotechnology [142]. We recently proposed
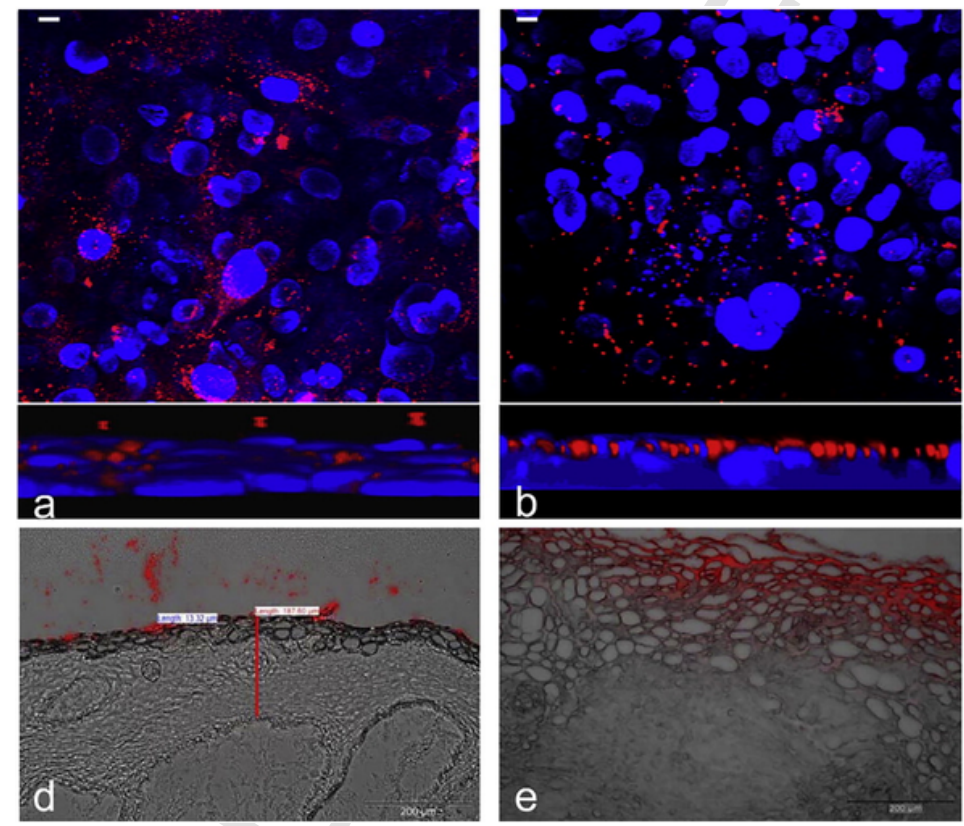

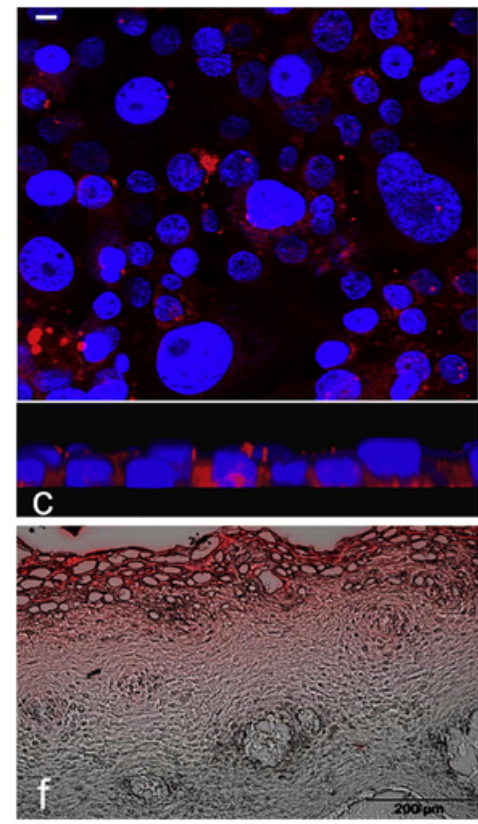

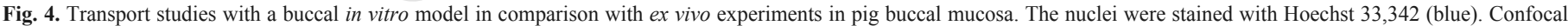

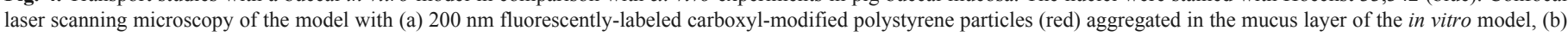

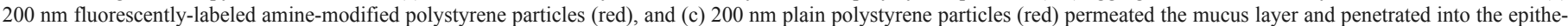

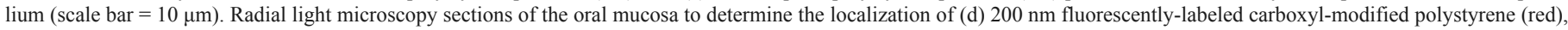

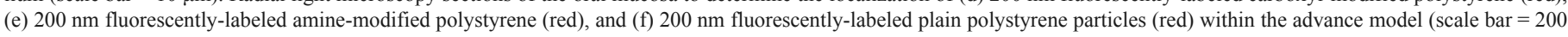

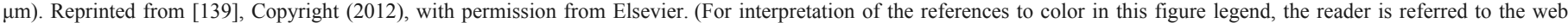
version of this article.) 
the incorporation of a mucus-like fluid in either HEC-1-A or CaSki cell monolayers in order to better understand the effects of such additional barrier in the permeation and epithelial accumulation of the candidate microbicide drug dapivirine [143]. The aqueous fluid was modified from Owen \& Katz [103] and contained 1.5\% ( $w / v)$ pig gastric mucin type II, $0.5 \%(w / v)$ glucose, $0.351 \%(w / v)$ sodium chloride, $0.2 \%(w / v)$ lactic acid, $0.14 \%(w / v)$ potassium hydroxide, $0.1 \%$ $(w / v)$ acetic acid, $0.04 \%(w / v)$ urea, $0.0222 \%(w / v)$ calcium hydroxide, $0.016 \%(w / v)$ glycerol and enough amount hydrochloride acid for $\mathrm{pH}$ 4.2. The artificial fluid did not change TEER up to at least $4 \mathrm{~h}$ and previous experiments demonstrated similar rheological behavior to native mucus [119]. Experiments using the described models showed that the presence of mucins had considerable impact in both the permeability and cell monolayer accumulation of dapivirine, either in suspension or associated to $170 \mathrm{~nm}$ PLGA nanoparticles (Fig. 5) [143]. For instance, $P_{\text {app }}$ mean values were around 2- to 4-fold lower in the presence of artificial fluid containing mucin, while drug levels found associated with cell monolayers dropped 5- to 11-times. These data highlight the impact of mucus in drug and nanocarriers transport although, as mentioned above, the proposed models may tend to overestimate mucus barrier usually found in vivo.

\section{Characterization techniques of mucus layer on cell-based mucosal models}

As discussed above, mucus may substantially influence the behavior of drugs and DDS when present in cell-based models. However, either when developing or for quality control purposes, it is essential to characterize the presence and properties of this biological barrier. In the following, we briefly describe different techniques to identify or to quantify the production of the mucus layer laid over cells. Furthermore, some methods proposed to measure the thickness of the mucus layer and to remove it to prove its presence and impact on drug or DDS permeability are also discussed. A summary of the different techniques used and selected references is presented in Table 2.

\subsection{Methods to identify the mucus layer}

Three main techniques have been commonly used to identify the presence of mucus on top of cell-based membranes. The first consists of staining acidic mucus components, namely mucin fibers, with Alcian blue or Toluidine blue reagents and microscopic observation $[43,55,74]$. Such experiments can be simply performed during the cell model development and/or at the end of the culture process. For instance, Hilgendorf et al. revealed qualitative differences in staining results as result of HT29-MTX cells initial seeding densities in co-cultures with Caco-2 [43]. The second qualitative technique is based on the utilization of scanning (SEM) or transmission (TEM) electron microscopy. Our group showed by using SEM the presence of mucus residues over co-culture of Caco-2 and HT29-MTX cells (Fig. 6A) [57]. Also, Walter et al. showed mucus-secretory granules in the apical side of cells using TEM, as represented in Fig. 6B [42].

The third method applied to the identification of mucus on cell-based models is by using immunofluorescence with anti-mucin antibody. Vllasaliu et al. have stained the secretory mucin, MUC-5A, in bronchial model composed of Calu-3 seeded in ALI configuration [144]. Chen et al. also showed with this technique that the production of mucus was higher when Caco-2/HT29-MTX cells where seeded on a 3D silk scaffold compared to cell seeding in 2D [65]. Fig. 7A shows that the mucin-type 2 (MUC2), represented in red, is more intense in the 3D scaffold. Costello et al. have further used anti-MUC2 antibody

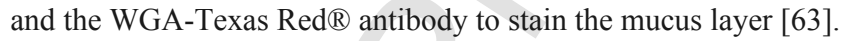

Another strategy to indirectly study the impact of the mucus layer is to wash cell-based models containing mucus and to analyze the consequences in terms of drug or DDS permeability. In this case, models are washed with HBSS and stirred [43,145] or washed with acetylcysteine [144] to cleave the disulfide bridges between mucin fibers. The impact of the mucus layer can be inferred by testing the permeability of drugs or DDS on washed and unwashed models. For instance, Vllasiliu et al. tested the permeability of nanoparticles made of chitosan on Calu-3 cell model in ALI and LCC configurations. They showed that the MAP (containing chitosan) induced higher permeability of Dextran-FITC on ALI model since this model was covered by a full mucus layer. Moreover, to confirm that permeability enhancement was due to the presence of mucus and not due to other factors, they treated the AIC Calu-3 cells with a mucolytic agent (acetylcysteine) in order to remove the mucus layer, prior to the application of MAP. Increased permeability for the model containing mucus as compared to washed cell-model provided evidence of the impact of the mucus layer. This technique was also used to prove the impact of the mucus layer on the permeability of lipophilic drugs such as testosterone. Indeed, the washing procedure increased the absorption rate of testosterone twofold across a monolayer of HT29-MTX cells whereas the permeability was not modified in the Caco-2 cells monolayer [146]. Interestingly, they also showed that TEER were similar after the washing step proving the integrity of monolayers.
A

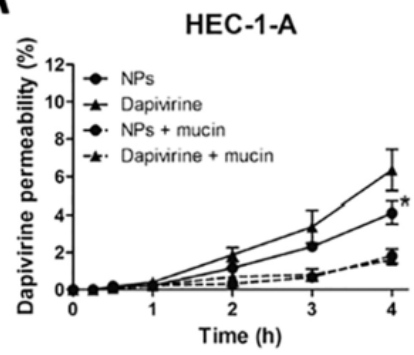

B

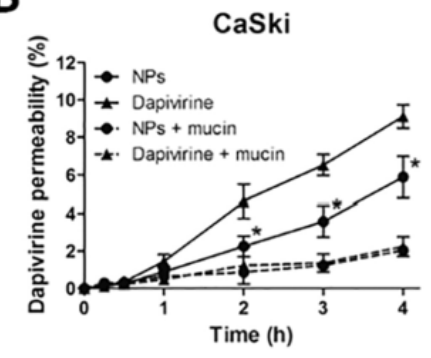

C

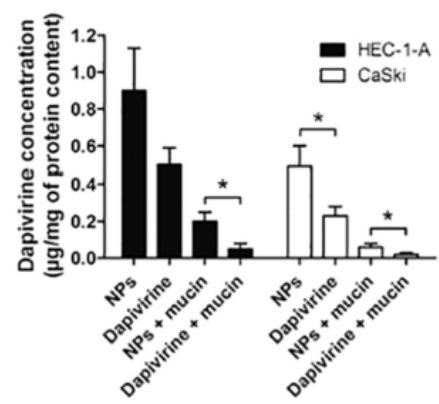

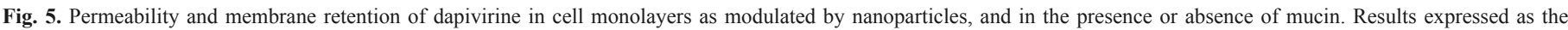

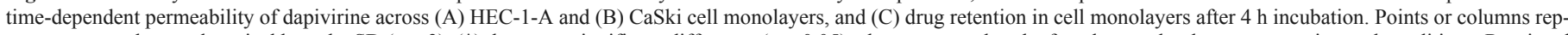

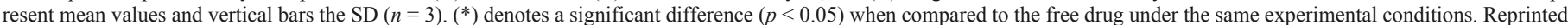
from [143], Copyright (2015), with permission from Acta Biomaterialia Inc. 
Table 2

Summary of techniques useful in identifying and quantifying mucus on cell-based barrier models.

\begin{tabular}{lll}
\hline & Qualitative methods & Reference \\
\hline Presence & Alcian blue/Toluidine blue & {$[4,42,43,54,55,74]$} \\
& Immunohistochemisty & {$[63,65,144]$} \\
\multirow{5}{*}{ Indirect } & SEM/TEM & {$[42,57,75,148]$} \\
& Washing & {$[43,144,146]$} \\
& Quantitative methods & \\
& RT-PCR (MUC1 and MUC2) & {$[22]$} \\
& qRT-PCR (MUC2) & {$[65]$} \\
& ELLA & {$[63,65,146]$} \\
& Periodic acid/Schiff & {$[42,54,55]$} \\
Thickness & Alcian Blue + Cross-section & {$[65]$} \\
\hline
\end{tabular}

\subsection{Methods to quantify the mucus layer}

Different quantitative techniques have been proposed to characterize in more detail the mucus layer on cell-based models. The measurement of the mucus layer thickness was performed by Chen et al. by using Alcian blue staining followed by cross-sectioning of cell-based models [65]. Sections were observed under a light microscope (Fig. 7B) and analyzed with Image J software. This simple yet powerful technique provides both qualitative and quantitative results in term of mucus thickness. Furthermore, Chen et al. showed that the thickness of the mucus layer above Caco-2/HT29-MTX cells set-up in 2D (around $4 \mu \mathrm{m}$ ) was significantly lower than the mucus thickness obtained in the 3D silk scaffold system (approximately $17 \mu \mathrm{m}$ ).

Reverse-transcription polymerase chain reaction (RT-PCR) [22] and quantitative RT-PCR $[65,66]$ have also been used to quantify the expression of the MUC2 mRNA. For instance, Chen et al. quantified with RT-PCR the mRNA expression of MUC2 as well as other important components like two tight junctions (ZO-1 and E-cadherin) and the villin protein, according to the time in culture. They showed that the expression of MUC2 was higher when Caco-2/HT29-MTX (ratio 66:33) cells were cultured on patterned 3D silk scaffolds instead of 2D Transwell®. This technique is useful but we must be used with caution since the amount of mRNA does not always reflect the quantity of the amount of protein actually produced. An interesting experiment would be to quantify the expression of MUC2 mRNA in function of different culture parameters as the initial goblet cells seeding or the time in culture. Another useful method encompasses the quantification of mucus secretion on Transwell ${ }^{\circledR}$ inserts by Enzyme-linked Lectin Assay (ELLA) $[63,65,146]$. In practical terms, the mucus layer is removed in different washing steps, being the complete removal checked with Alcian blue or Toluidine blue staining. Then, samples are incubated with WGA-peroxidase and $O$-phenylenediamine reagents, and the absorbance is read. Using a standard curve of porcine mucin, the mucin concentration on cell-based model is quantified. The last quantitative technique is based on the use of the periodic acid/Schiff reagent $[42,54,55]$. The principle of this technique is the same as Alcian blue or ELLA and consists of stained substances of mucus as glycoproteins, glycolipids and mucins.

The different qualitative and quantitative techniques described above are not often used and, even less, used in tandem. Depending on the goal of the research, the identification of the mucus layer can be more or less relevant. For example, when a new in vitro model is developed, it seems crucial to identify and quantify the production of mucus. Thereby, we have seen that the presence of the mucus layer influences the robustness of the epithelium through variation of the TEER and consequently, influences the permeability of drugs. On the other hand, cell-based models previously optimized are often used to test the performance of new DDS. However, especially when DDS are developed to increase the diffusion within the mucus network, the identification of the mucus layer is still important. This is even truer since different authors have reported that the behavior of cell-based models varies among different laboratories. Srinivan et al. identified many differences of TEER measurements of intestinal and pulmonary in vitro models between laboratories [34]. Concerning the small intestine model, our group has recently showed that the property of the Transwell ${ }^{\circledR}$ system may completely modify the behavior of the epithelial barrier [147]. Moreover, as explained in Section 2.3.2, the configuration of Calu-3 cells on Transwell ${ }^{\circledR}$ system also determines mucus production. Overall, the proof that the in vitro barrier models produce mucus in a consistent way is crucial to their development.

\section{Conclusions and future perspectives}

In this manuscript, we provided a range of models surrogating mucosa but evidenced that the consideration of a mucus layer is often neglected. This observation is obviously variable depending on the route of administration and thus on the attempts to reproduce mucosae in vitro. The intestinal barrier has been studied for a long time and new promising techniques have been developed. However, their
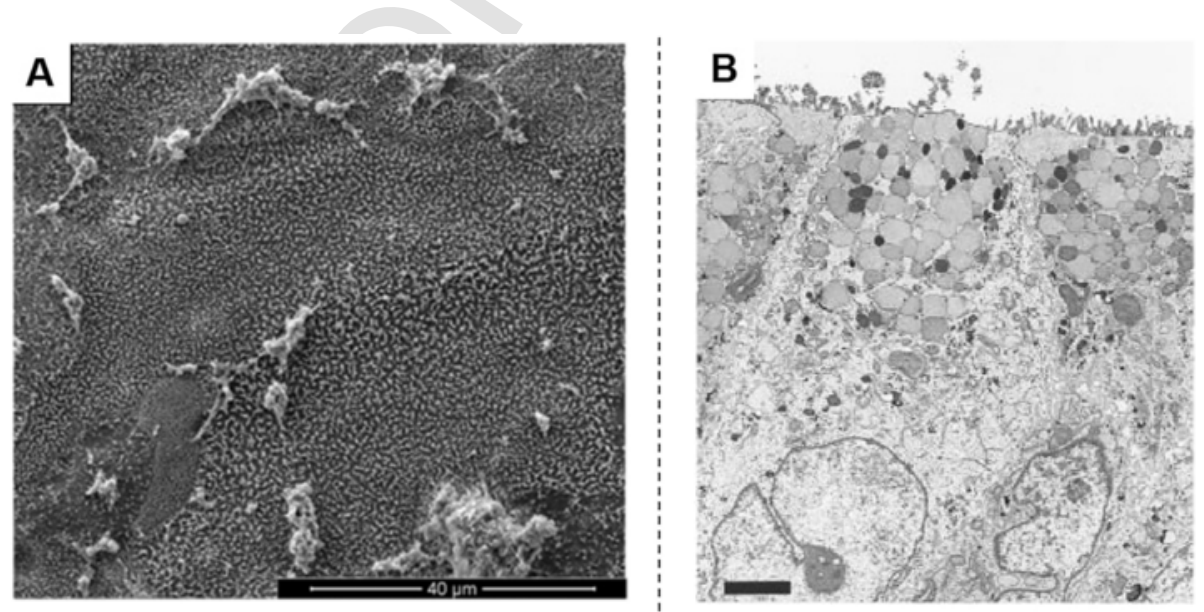

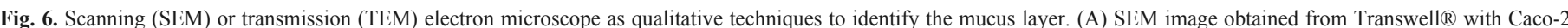

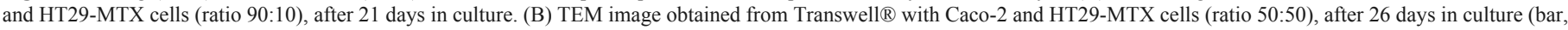
$3.1 \mu \mathrm{m})$. Image A and Image B are reprinted from Publications [42,57] respectively, with permission from Elsevier. 
A

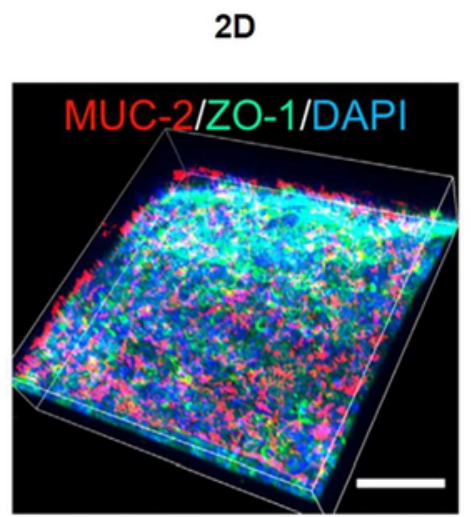

B

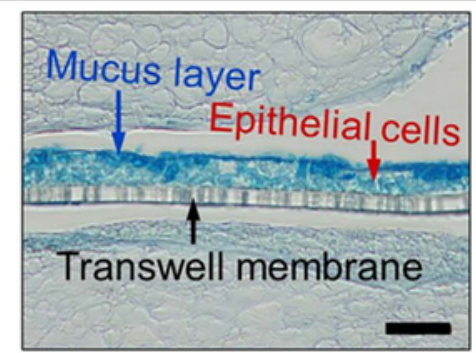

Thickness: $4 \mu \mathrm{m}$

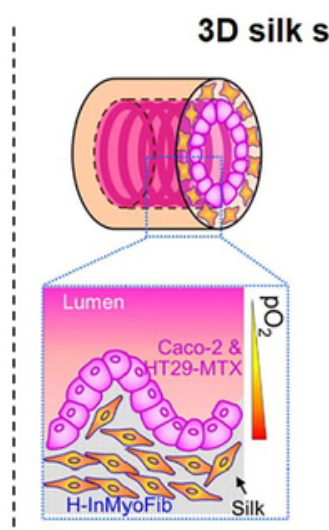

3D silk scaffold
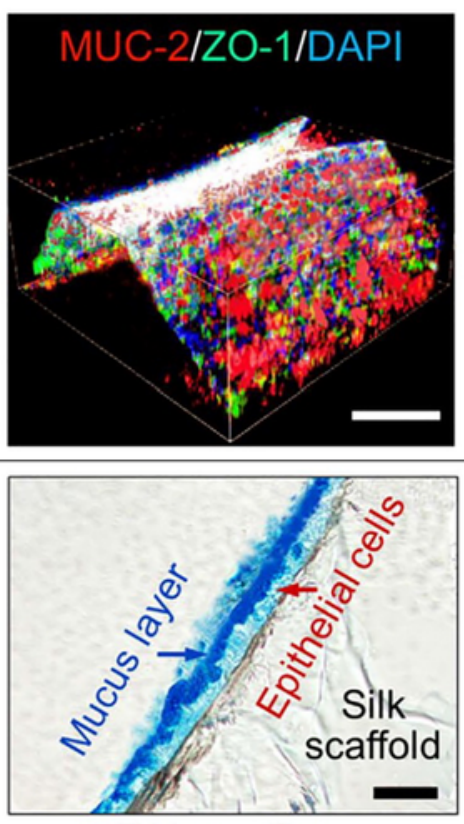

Thickness: $17 \mu \mathrm{m}$

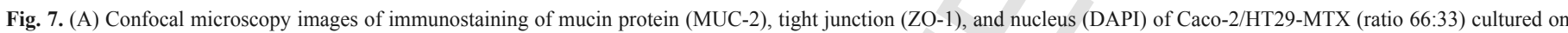

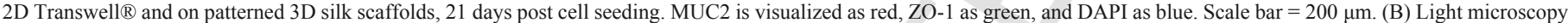

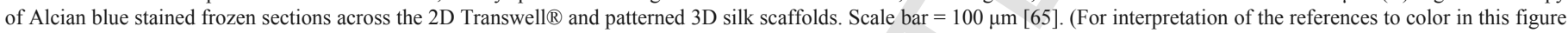
legend, the reader is referred to the web version of this article.)

reproducibility and robustness are not yet completely defined. Other models mimicking the mucosa of the cervico-vaginal tract, the respiratory tract or the buccal mucosa are not exhaustive since their routes of administration are less used in practice. Thereby, the number of available cell lines, for instance, is lower and the development of cell-based model more tedious.

The consideration of the mucus layer on in vitro mucosal barriers is not always the case whereas its consideration is crucial in order to develop new DDS. Nano- or micro-particles are used to protect sensitive active molecules or to increase their permeability. Although a paradigm still exists between MPP and MAP, they are currently one of the most attractive solutions to spread up the development of mucosal drug delivery.

Moreover, the lack of well-characterized models-producing mucus and their reproducibility is still an issue. In order to demonstrate that a nanocarrier improves the permeability of an active molecule by increasing its mucus diffusion, a model with the presence and the right amount of mucus has to be used. The development of in vitro models which include all the components of the mucosal barrier and obviously the mucus layer, will presumably help in developing new medicines.

\section{Acknowledgments}

The authors would like to acknowledge the Fonds Leon Fredericq for the financial support. Anna Lechanteur is a Marie-Curie COFUND postdoctoral fellow at the University of Liege, co-funded by the European Union. This work was also financed by FEDER - Fundo Europeu de Desenvolvimento Regional funds through the COMPETE 2020 - Operational Programme for Competitiveness and Internationalisation (POCI), Portugal 2020, and by Portuguese funds through FCT - Fundação para a Ciência e a Tecnologia/Ministério da
Ciência, Tecnologia e Inovação in the framework of the projects "Institute for Research and Innovation in Health Sciences" (POCI-01-0145-FEDER-007274). José das Neves gratefully acknowledges Fundação para a Ciência e a Tecnologia, Portugal for financial support (grant SFRH/BPD/92934/2013).

\section{References}

[1] K. Khanvilkar, M. Donovan, D. Flanagan, Drug transfer through mucus, Adv. Drug Deliv. Rev. 48 (2001) 173-193.

[2] F. Laffleur, A. Bernkop-Schnurch, Strategies for improving mucosal drug delivery, Nanomedicine 8 (2013) 2061-2075.

[3] A. Beule, Physiology and pathophysiology of respiratory mucosa of the nose and the paranasal sinuses, GMS Curr. Top. Otorhinolaryngol. Head Neck Surg. 9 (2010) 1-24.

[4] F. Antunes, F. Andrade, F. Araujo, D. Ferreira, B. Sarmento, Establishment of a triple co-culture in vitro cell models to study intestinal absorption of peptide drugs, Eur. J. Pharm. Biopharm. 83 (2013) 427-435.

[5] P. Lundquist, P. Artursson, Oral absorption of peptides and nanoparticles across the human intestine: opportunities, limitations and studies in human tissues, Adv. Drug Deliv. Rev. 106 (2016) 256-276.

[6] K. Netsomboon, A. Bernkop-Schnurch, Mucoadhesive vs. mucopenetrating particulate drug delivery, Eur. J. Pharm. Biopharm. 98 (2015) 76-89.

[7] R.A. Cone, Barrier properties of mucus, Adv. Drug Deliv. Rev. 61 (2009) 75-85.

[8] B. Sarmento, F. Andrade, S.B. da Silva, F. Rodrigues, J. das Neves, D. Ferreira, Cell-based in vitro models for predicting drug permeability, Expert Opin. Drug Metab. Toxicol. 8 (2012) 607-621.

[9] B. Sarmento, Concepts and Models for Drug Permeability Studies: Cell and Tissue Based In Vitro Culture Models, 2015.

[10] S.N. Bhatia, D.E. Ingber, Microfluidic organs-on-chips, Nat. Biotechnol. 32 (2014) 760-772.

[11] S. Shafaie, V. Hutter, M.T. Cook, M.B. Brown, D.Y. Chau, In vitro cell models for ophthalmic drug development applications, BioResearch 5 (2016) 94-108.

[12] J. Barar, M. Asadi, S. Mortazavi-Tabatabaei, Y. Omidi, Ocular drug delivery; impact of in vitro cell culture models, J. Ophthalmic Vis. Res. 4 (2009) 238-252. 
[13] G. Flemström, E. Kivilaakso, Demonstration of a $\mathrm{pH}$ gradient at the luminal surface of rat duodenum in vivo and its dependence on mucosal alkaline secretion, Gastroenterology 4 (1983) 787-794.

[14] C. Atuma, V. Strugala, A. Allen, L. Holm, The adherent gastrointestinal mucus gel layer: thickness and physical state in vivo, Am. J. Physiol. Gastrointest. Liver Physiol. 280 (2001) G922-G929.

[15] M.E. Johansson, D. Ambort, T. Pelaseyed, A. Schutte, J.K. Gustafsson, A. Ermund, D.B. Subramani, J.M. Holmen-Larsson, K.A. Thomsson, J.H. Bergstrom, S. van der Post, A.M. Rodriguez-Pineiro, H. Sjovall, M. Backstrom, G.C. Hansson, Composition and functional role of the mucus layers in the intestine, Cell. Mol. Life Sci. 68 (2011) 3635-3641.

[16] T. Pelaseyed, J.H. Bergstrom, J.K. Gustafsson, A. Ermund, G.M. Birchenough, A. Schutte, S. van der Post, F. Svensson, A.M. Rodriguez-Pineiro, E.E. Nystrom, C. Wising, M.E. Johansson, G.C. Hansson, The mucus and mucins of the goblet cells and enterocytes provide the first defense line of the gastrointestinal tract and interact with the immune system, Immunol. Rev. 260 (2014) 8-20.

[17] S. Cornick, A. Tawiah, K. Chadee, Roles and regulation of the mucus barrier in the gut, Tissue Barriers 3 (2015), e982426.

[18] M.E. Johansson, M. Phillipson, J. Petersson, A. Velcich, L. Holm, G.C. Hansson, The inner of the two Muc2 mucin-dependent mucus layers in colon is devoid of bacteria, Proc. Natl. Acad. Sci. U. S. A. 105 (2008) 15064-15069.

[19] R. Bansil, The biology of mucus: synthesis, composition and organization, Adv. Drug Deliv. Rev. (2017), in revision.

[20] C.M. Lehr, The role of mucus on drug transport and potential to affect PK/PD outcomes, Adv. Drug Deliv. Rev. (2017), in revision.

[21] H.H. Sigurdsson, J. Kirch, C.M. Lehr, Mucus as a barrier to lipophilic drugs, Int. J. Pharm. 453 (2013) 56-64.

[22] I. Behrens, P. Stenberg, P. Artursson, T. Kissel, Transport of lipophilic drug molecules in a new mucus-secreting cell culture model based on HT29-MTX cells, Pharm. Res. 18 (2001) 1138-1145

[23] N. Shrestha, F. Araújo, B. Sarmento, J. Hirvonen, H.A. Santos, Cell-Based In Vitro Models for Buccal Permeability Studies, 201631-40.

[24] D. Dziemiańczyk, S.Z. Grabowska, R. Balicki, Evaluation of secretory mucin concentration of patients with squamous cell carcinoma oral cavity, Rocz. Akad. Med. Bialymst. 50 (2005) 334-338.

[25] A. Allen, W. Cunliffe, J. Pearson, C. Venables, The adherent gastric mucus gel barrier in man and changes in peptic ulceration, J. Intern. Med. Suppl. 732 (1990) 83-90.

[26] S. Karam, C.F. Leblond, Dynamics of epithelial cells in the corpus of the mouse stomach, Anat. Rec. 236 (1993) 259-279.

[27] T. dos Santos, B.N. Lourenço, J. Coentro, P.L. Granja, Cell-based in vitro models for gastric permeability studies, in: B. Sarmento (Ed.), Concepts and Models for Drug Permeability Studies, 2016, pp. 41-56.

[28] G.J. Tortora, B.H. Derrickson, in: J.W.a. Sons (Ed.), Principles of Anatomy and Physiology, 2008.

[29] J. Basque, D. Ménard, Establishment of culture systems of human gastric epithelium for the study of pepsinogen and gastric lipase synthesis and secretion, Microsc. Res. Tech. 48 (2000) 293-302.

[30] J. Basque, M. Chénard, P. Chailer, D. Ménard, Gastric cancer cell lines as models to study human digestive functions, J. Cell. Biochem. 81 (2011) 241-251.

[31] P. Chailler, D. Menard, Establishment of human gastric epithelial (HGE) cell lines exhibiting barrier function, progenitor, and prezymogenic characteristics, J. Cell. Physiol. 202 (2005) 263-274.

[32] N. Okayama, M.R. Fowler, S.R. Jennings, R. Specian, B. Alexander, T.H. Jasckson, Characterization of JOK-1, a human gastric epithelial cell line, In Vitro Cell. Dev. Biol. Anim. 36 (2000) 228-234.

[33] T. Oshima, H. Miwa, T. Joh, Aspirin induces gastric epithelial barrier dysfunction by activating p38 MAPK via claudin-7, Am. J. Physiol. Cell Physiol. 295 (2008) C800-C806.

[34] B. Srinivasan, A.R. Kolli, M.B. Esch, H.E. Abaci, M.L. Shuler, J.J. Hickman, TEER measurement techniques for in vitro barrier model systems, J. Lab. Autom. 20 (2015) 107-126.

[35] M. Lemieux, F. Bouchard, P. Gosselin, J. Paquin, M.A. Mateescu, The NCI-N87 cell line as a gastric epithelial barrier model for drug permeability assay, Biochem. Biophys. Res. Commun. 412 (2011) 429-434.

[36] C. Pereira, J. Costa, B. Sarmento, F. Araújo, Cell-Based In Vitro Models for Intestinal Permeability Studies, 201657-81.

[37] L.G. van der Flier, H. Clevers, Stem cells, self-renewal, and differentiation in the intestinal epithelium, Annu. Rev. Physiol. 71 (2009) 241-260.

[38] M. Pinto, M.D. Appay, P. Simon-Assan, G. Chevalier, N. Dracopoli, J. Fogh, A. Zweibaum, Enterocytic differentiation of cultured human colon cancer cells by replacement of glucose by galactose in the medium, Biol. Cell. 47 (1982) 193-196.

[39] A.C. Groo, K. Mircheva, J. Bejaud, C. Ailhas, I. Panaiotov, P. Saulnier, T. Ivanova, F. Lagarce, Development of 2D and 3D mucus models and their interactions with mucus-penetrating paclitaxel-loaded lipid nanocapsules, Pharm. Res. 31 (2014) 1753-1765.
[40] T. Lesuffleur, A. Babat, C. Luccioni, J. Beaumatin, M. Clair, A. Kornowski, E. Dussaulx, B. Dutrillaux, A.J. Zweibaum, Growth adaptation to methotrexate of HT-29 human colon carcinoma cells is associated with their ability to differentiate into columnar absorptive and mucus-secreting cells, Cell Biol. 115 (1991) 1409-1418.

[41] T. Lesuffleur, N. Porchet, J.-P. Aubert, D. Swallow, J. Gum, Y. Kim, F. Real, A. Zweibaum, Differential expression of the human mucin genes MUC1 to MUC5 in relation to growth and differentiation of different mucus-secreting HT-29 cell subpopulations, J. Cell Sci. 106 (1993) 771-783.

[42] E. Walter, S. Janich, B. Roessler, J. Hifinger, J. Amidon, HT29-MTX/Caco-2 cocultures as an in vitro model for the intestinal epithelium: in vitro - in vivo correlation with permeability data from rats and humans, J. Pharm. Sci. 85 (1996) 1070-1076.

[43] C. Hilgendorf, S.-L. H., C. Regardh, E. Lipka, G. Amidon, P. Langguth, Caco-2 versus Caco-2/HT29-MTX co-cultured cell lines: permeabilities via diffusion, inside- and outside-directed carrier-mediated transport, J. Pharm. Sci. 89 (1999) 63-75.

[44] S. Kerneis, A. Bogdanova, J.-P. Kraehenbuhl, E. Pringault, Conversion by Peyer's patch lymphocytes of human enterocytes into $\mathrm{M}$ cells that transport bacteria, Science 277 (1997) 949-952.

[45] E. Gullberg, M. Leonard, J. Karlsson, A.M. Hopkins, D. Brayden, A.W. Baird, P. Artursson, Expression of specific markers and particle transport in a new human intestinal M-cell model, Biochem. Biophys. Res. Commun. 279 (2000) 808-813.

[46] A. des Rieux, V. Fievez, I. Theate, J. Mast, V. Preat, Y.J. Schneider, An improved in vitro model of human intestinal follicle-associated epithelium to study nanoparticle transport by M cells, Eur. J. Pharm. Sci. 30 (2007) 380-391.

[47] A. des Rieux, E.G. Ragnarsson, E. Gullberg, V. Preat, Y.J. Schneider, P. Artursson, Transport of nanoparticles across an in vitro model of the human intestinal follicle associated epithelium, Eur. J. Pharm. Sci. 25 (2005) 455-465.

[48] A. Sosnik, J.d. Neves, B. Sarmento, Mucoadhesive polymers in the design of nano-drug delivery systems for administration by non-parenteral routes: a review, Prog. Polym. Sci. 39 (2014) 2030-2075.

[49] F. Antunes, F. Andrade, F. Araújo, D. Ferreira, B. Sarmento, Establishment of a triple co-culture in vitro cell models to study intestinal absorption of peptide drugs, Eur. J. Pharm. Biopharm. 83 (2013) 427-435.

[50] J. Forstner, G. Forstner, Gastrointestinal mucus, in: L.R. Johnson (Ed.), Physiology of the Gastrointestinal Tract, 1994, pp. 1255-1283.

[51] C. Schimpel, B. Teubl, M. Absenger, C. Meindl, E. Frohlich, G. Leitinger, A. Zimmer, E. Roblegg, Development of an advanced intestinal in vitro triple culture permeability model to study transport of nanoparticles, Mol. Pharm. 11 (2014) 808-818.

[52] K.A. Fitzgerald, M. Malhotra, C.M. Curtin, O.B. FJ, O.D. CM, Life in 3D is never flat: 3D models to optimise drug delivery, J. Control. Release 215 (2015) $39-54$.

[53] F. Pampaloni, E. Reynaud, E. Stelzer, The third dimension bridges the gap between cell culture and live tissue, Nat. Rev. Mol. Cell Biol. 8 (2007) 839-845.

[54] N. Li, D. Wang, Z. Sui, X. Qi, L. Ji, X. Wang, L. Yang, Development of an improved three-dimensional in vitro intestinal mucosa model for drug absorption evaluation, Tissue Eng. Part C Methods 19 (2013) 708-719.

[55] F. Leonard, E.M. Collnot, C.M. Lehr, A three-dimensional coculture of enterocytes, monocytes and dendritic cells to model inflamed intestinal mucosa in vitro, Mol. Pharm. 7 (2010) 2103-2119.

[56] E. Nagel, M. Bartels, R. Pichlmayr, Scanning electron-microscopic lesions in Crohn's disease: relevance for the interpretation of postoperative recurrence, Gastroenterology 108 (1995) 376-382.

[57] C. Pereira, F. Araujo, C.C. Barrias, P.L. Granja, B. Sarmento, Dissecting stromal-epithelial interactions in a 3D in vitro cellularized intestinal model for permeability studies, Biomaterials 56 (2015) 36-45.

[58] M. Lee, J.C. Dunn, B.M. Wu, Scaffold fabrication by indirect three-dimensional printing, Biomaterials 26 (2005) 4281-4289.

[59] L. Wang, S.K. Murthy, W.H. Fowle, G.A. Barabino, R.L. Carrier, Influence of micro-well biomimetic topography on intestinal epithelial Caco-2 cell phenotype, Biomaterials 30 (2009) 6825-6834.

[60] L. Wang, S.K. Murthy, G.A. Barabino, R.L. Carrier, Synergic effects of crypt-like topography and ECM proteins on intestinal cell behavior in collagen based membranes, Biomaterials 31 (2010) 7586-7598.

[61] J.H. Sung, J. Yu, D. Luo, M.L. Shuler, J.C. March, Microscale 3-D hydrogel scaffold for biomimetic gastrointestinal (GI) tract model, Lab Chip 11 (2011) 389-392.

[62] J. Yu, S. Peng, D. Luo, J.C. March, In vitro 3D human small intestinal villous model for drug permeability determination, Biotechnol. Bioeng. 109 (2012) 2173-2179.

[63] C.M. Costello, J. Hongpeng, S. Shaffiey, J. Yu, N.K. Jain, D. Hackam, J.C. March, Synthetic small intestinal scaffolds for improved studies of intestinal differentiation, Biotechnol. Bioeng. 111 (2014) 1222-1232. 
[64] C.M. Costello, R.M. Sorna, Y.L. Goh, I. Cengic, N.K. Jain, J.C. March, 3-D intestinal scaffolds for evaluating the therapeutic potential of probiotics, Mol. Pharm. 11 (2014) 2030-2039.

[65] Y. Chen, Y. Lin, K.M. Davis, Q. Wang, J. Rnjak-Kovacina, C. Li, R.R. Isberg, C.A. Kumamoto, J. Mecsas, D.L. Kaplan, Robust bioengineered 3D functional human intestinal epithelium, Sci. Rep. 5 (2015) 13708.

[66] A.L. Kauffman, A.V. Gyurdieva, J.R. Mabus, C. Ferguson, Z. Yan, P.J. Hornby, Alternative functional in vitro models of human intestinal epithelia, Front. Pharmacol. 4 (2013) 79.

[67] M.J. Workman, M.M. Mahe, S. Trisno, H.M. Poling, C.L. Watson, N. Sundaram, C.-F. Chang, J. Schiesser, P. Aubert, E.G. Stanley, A.G. Elefanty, Y. Miyaoka, M.A. Mandegar, B.R. Conklin, M. Neunlist, S.A. Brugmann, M.A. Helmrath, J.M. Wells, Engineered human pluripotent-stem-cell-derived intestinal tissues with a functional enteric nervous system, Nat. Med. (2016).

[68] J. Pusch, M. Votteler, S. Gohler, J. Engl, M. Hampel, H. Walles, K. Schenke-Layland, The physiological performance of a three-dimensional model that mimics the microenvironment of the small intestine, Biomaterials 32 (2011) 7469-7478.

[69] J. Kasper, M.I. Hermanns, C. Cavelius, A. Kraegeloh, T. Jung, R. Danzebrink, R.E. Unger, C.J. Kirkpatrick, The role of the intestinal microvasculature in inflammatory bowel disease: studies with a modified Caco- 2 model including endothelial cells resembling the intestinal barrier in vitro, Int. J. Nanomedicine 11 (2016) 6353-6364.

[70] M. Boegh, H.M. Nielsen, Mucus as a barrier to drug delivery - understanding and mimicking the barrier properties, Basic Clin. Pharmacol. Toxicol. $116(2015)$ 179-186.

[71] J. Kirch, A. Schneider, B. Abou, A. Hopf, U.F. Schaefer, M. Schneider, C. Schall, C. Wagner, C.M. Lehr, Optical tweezers reveal relationship between microstructure and nanoparticle penetration of pulmonary mucus, Proc. Natl. Acad. Sci. U. S. A. 109 (2012) 18355-18360.

[72] Y. Kim, A. Varki, Perspectives on the significance of altered glycosylation of glycoproteins in cancer, Glycoconj. J. 14 (1997) 569-576.

[73] A. Beduneau, C. Tempesta, S. Fimbel, Y. Pellequer, V. Jannin, F. Demarne, A. Lamprecht, A tunable Caco-2/HT29-MTX co-culture model mimicking variable permeabilities of the human intestine obtained by an original seeding procedure, Eur. J. Pharm. Biopharm. 87 (2014) 290-298.

[74] F. Araujo, B. Sarmento, Towards the characterization of an in vitro triple co-culture intestine cell model for permeability studies, Int. J. Pharm. 458 (2013) 128-134.

[75] F. Araujo, C. Pereira, J. Costa, C. Barrias, P.L. Granja, B. Sarmento, In vitro M-like cells genesis through a tissue-engineered triple-culture intestinal model, J. Biomed. Mater. Res. B Appl. Biomater. 104 (2015) 782-788.

[76] J.B. Lee, S.H. Son, M.C. Park, T.H. Kim, M.G. Kim, S.D. Yoo, S. Kim, A novel in vitro permeability assay using three-dimensional cell culture system, J. Biotechnol. 205 (2015) 93-100.

[77] B. Rubin, Physiology of airway mucus clearance, Respir. Care 47 (2002) 761-768.

[78] L.R. Hanson, W.H. Frey II, Intranasal delivery bypasses the blood-brain barrier to target therapeutic agents to the central nervous system and treat neurodegenerative disease, BMC Neurosci. 9 (Suppl. 3) (2008) S5.

[79] W. Wilson, M. Allansmith, Rapid, atraumatic method for obtaining nasal mucus samples, Ann. Otol. Rhinol. Laryngol. 85 (1976) 391-393.

[80] F. Sousa, P. Castro, Cell-Based In Vitro Models for Nasal Permeability Studies, 201683-100

[81] U. Werner, T. Kissel, Development of human nasal epithelial cell culture model and its suitability for transport and metabolism studies under in vitro conditions, Pharm. Res. 12 (1995) 565-571.

[82] T. Kissel, U. Werner, Nasal delivery of peptides: an in vitro cell culture model for the investigation of transport and metabolism in human nasal epithelium, J. Control. Release 53 (1998) 195-203.

[83] S. Dimova, M.E. Brewster, M. Noppe, M. Jorissen, P. Augustijns, The use of human nasal in vitro cell systems during drug discovery and development, Toxicol. in Vitro 19 (2005) 107-122.

[84] F. Andrade, J. Albuquerque, A.V. Nascimento, Cell-Based In Vitro Models for Pulmonary Permeability Studies, 2016101-113.

[85] S.K. Lai, Y.Y. Wang, J. Hanes, Mucus-penetrating nanoparticles for drug and gene delivery to mucosal tissues, Adv. Drug Deliv. Rev. 61 (2009) 158-171.

[86] K.J. Elbert, U. Schafer, H. Schafers, K.-J. Kim, V. Lee, C.M. Lehr, Monolayers of human alveolar epithelial cells in primary culture for pulmonary absorption and transport studies, Pharm. Res. 16 (1999).

[87] B. Forbes, C. Ehrhardt, Human respiratory epithelial cell culture for drug delivery applications, Eur. J. Pharm. Biopharm. 60 (2005) 193-205.

[88] C. de Souza Carvalho, N. Daum, C.M. Lehr, Carrier interactions with the biological barriers of the lung: advanced in vitro models and challenges for pulmonary drug delivery, Adv. Drug Deliv. Rev. 75 (2014) 129-140.

[89] M. Hittinger, J. Juntke, S. Kletting, N. Schneider-Daum, C. de Souza Carvalho, C.M. Lehr, Preclinical safety and efficacy models for pulmonary drug delivery of antimicrobials with focus on in vitro models, Adv. Drug Deliv. Rev. 85 (2015) 44-56.

[90] J. Fiegel, C. Ehrhardt, U. Schaefer, C.M. Lehr, J. Hanes, Large porous particle impingement on lung epithelial cell monolayers - toward improved particle characterization in the lung, Pharm. Res. 20 (2003) 788-796.

[91] C.I. Grainger, L.L. Greenwell, D.J. Lockley, G.P. Martin, B. Forbes, Culture of Calu-3 cells at the air interface provides a representative model of the airway epithelial barrier, Pharm. Res. 23 (2006) 1482-1490.

[92] M.E. Kreft, U.D. Jerman, E. Lasic, N. Hevir-Kene, T.L. Rizner, L. Peternel, K. Kristan, The characterization of the human cell line Calu-3 under different culture conditions and its use as an optimized in vitro model to investigate bronchial epithelial function, Eur. J. Pharm. Sci. 69 (2015) 1-9.

[93] M. Rose, J. Voynow, Respiratory tract mucin genes and mucin glycoproteins in health and disease, Physiol. Rev. 86 (2006) 245-278.

[94] T. Krunkosky, B. Fischer, L. Martin, N. Jones, N. Akleyn, K. Adler, Effects of TNF-a on expression of ICAM-1 in human airway epithelial cells in vitro, Am. J. Respir. Cell Mol. Biol. 22 (2000) 685-692.

[95] P. Marrazzo, S. Maccari, A. Taddei, L. Bevan, J. Telford, M. Soriani, A. Pezzicoli, 3D reconstruction of the human airway mucosa in vitro as an experimental model to study NTHi infections, PLoS One 11 (2016), e0153985.

[96] K.L. Sellgren, E.J. Butala, B.P. Gilmour, S.H. Randell, S. Grego, A biomimetic multicellular model of the airways using primary human cells, Lab Chip 14 (2014) 3349-3358

[97] J. Hanes, J. Demeester, Drug and gene delivery to mucosal tissues: the mucus barrier, Adv. Drug Deliv. Rev. 61 (2009) 73-74.

[98] J.M. Steinbach, Protein and oligonucleotide delivery systems for vaginal microbicides against viral STIs, Cell. Mol. Life Sci. 72 (2015) 469-503.

[99] J. das Neves, Vaginal Delivery of Biopharmaceuticals, in: J. das Neves, B. Sarmento (Eds.), Mucosal Delivery of Biopharmaceuticals: Biology, Challenges and Strategies, Springer, New York, NY, 2014, pp. 261-280

[100]

D.F. Katz, A. Yuan, Y. Gao, Vaginal drug distribution modeling, Adv. Drug Deliv. Rev. 92 (2015) 2-13.

[101]

L.M. Ensign, R. Cone, J. Hanes, Nanoparticle-based drug delivery to the vagina: a review, J. Control. Release 190 (2014) 500-514.

[102]

J. Das Neves, R. Palmeira-de-Oliveira, A. Palmeira-de-Oliveira, F. Rodrigues, B. Sarmento, Vaginal mucosa and drug delivery, in: V.V. Khutoryanskiy (Ed.), Mucoadhesive Materials and Drug Delivery Systems, 2014.

[103]

D.H. Owen, D.F. Katz, A vaginal fluid simulant, Contraception 59 (1999) 91-95.

[104]

S.A. McKinley, A. Chen, F. Shi, S. Wang, P.J. Mucha, M.G. Forest, C.S. Lai, Modeling neutralization kinetics of HIV by broadly neutralizing monoclonal antibodies in genital secretions coating the cervicovaginal mucosa, PLoS One 6 (2014), e100598.

[105]

E.R. Boskey, R. Cone, K.J. Whaley, T.R. Moench, Origins of vaginal acidity: high $\mathrm{D} / \mathrm{L}$ lactate ratio is consistent with bacteria being the primary source, Hum. Reprod. 16 (2001) 1809-1813.

[106]

Z. Vanic, N. Skalko-Basnet, Nanopharmaceuticals for improved topical vaginal therapy: can they deliver?, Eur. J. Pharm. Sci. 50 (2013) 29-41.

[107]

A. Machado, J.d. Neves, Tissue-Based In Vitro and Ex Vivo Models for Vaginal Permeability Studies, 2016273-308.

[108]

R.M. Machado, A. Palmeira-de-Oliveira, C. Gaspar, J. Martinez-de-Oliveira, R. Palmeira-de-Oliveira, Studies and methodologies on vaginal drug permeation, Adv. Drug Deliv. Rev. 92 (2015) 14-26.

[109]

G.I. Gorodeski, M.F. Romero, U. Hopfer, E.A. Rorke, W.H. Utian, R.L. Eckert, Human uterine cervical epithelial cells grown on permeable support - a new model for the study of differentiation, Differenciation 56 (1994) 107-118.

[110]

G.I. Gorodeski, R.L. Eckert, W.H. Utian, E.A. Rorke, Maintenance of in vivo-like keratin expression, sex steroid responsiveness and estrogen receptor expression in cultured human ectocervical epithelial cells, Endocrinology 126 (1990) 399-406.

[111]

J. das Neves, F. Araujo, F. Andrade, J. Michiels, K.K. Arien, G. Vanham, M. Amiji, M.F. Bahia, B. Sarmento, In vitro and ex vivo evaluation of polymeric nanoparticles for vaginal and rectal delivery of the anti-HIV drug dapivirine, Mol. Pharm. 10 (2013) 2793-2807.

[112]

Y. Gali, K.K. Arien, M. Praet, R. Van den Bergh, M. Temmerman, O. Delezay, $\mathrm{G}$. Vanham, Development of an in vitro dual-chamber model of the female genital tract as a screening tool for epithelial toxicity, J. Virol. Methods 165 (2010) 186-197.

[113]

C. Grammen, P. Augustijns, J. Brouwers, In vitro profiling of the vaginal permeation potential of anti-HIV microbicides and the influence of formulation excipients, Antivir. Res. 96 (2012) 226-233. 
[116]

H. Fatakdawala, S.A. Uhland, Hydrogen peroxide mediated transvaginal drug delivery, Int. J. Pharm. 409 (2011) 121-127.

[117]

J. Griessinger, S. Dunnhaupt, B. Cattoz, P. Griffiths, S. Oh, S.B. Gomez, M. Wilcox, J. Pearson, M. Gumbleton, A. Bernkop-Schnurch, Methods to determine the interactions of micro- and nanoparticles with mucus, Eur. J. Pharm. Biopharm. 96 (2015).

[118]

T. Furst, G.R. Dakwar, E. Zagato, A. Lechanteur, K. Remaut, B. Evrard, K. Braeckmans, G. Piel, Freeze-dried mucoadhesive polymeric system containing pegylated lipoplexes: towards a vaginal sustained released system for siRNA, J. Control. Release 236 (2016) 68-78.

[119]

J. das Neves, C.M. Rocha, M.P. Goncalves, R.L. Carrier, M. Amiji, M.F. Bahia, B. Sarmento, Interactions of microbicide nanoparticles with a simulated vaginal fluid, Mol. Pharm. 9 (2012) 3347-3356.

[120]

F. Araújo, J. das Neves, J.P. Martins, P.L. Granja, H.A. Santos, B. Sarmento, Functionalized materials for multistage platforms in the oral delivery of biopharmaceuticals, Prog. Mater. Sci. (2017).

[121]

M.E. Johansson, H. Sjovall, G.C. Hansson, The gastrointestinal mucus system in health and disease, Nat. Rev. Gastroenterol. Hepatol. 10 (2013) 352-361.

[122]

B.H. Bajka, N.M. Rigby, K.L. Cross, A. Macierzanka, A.R. Mackie, The influence of small intestinal mucus structure on particle transport ex vivo, Colloids Surf. B: Biointerfaces 135 (2015) 73-80

M. Boegh, S.G. Baldursdóttir, A. Müllertz, H.M. Nielsen, Property profiling of biosimilar mucus in a novel mucus-containing in vitro model for assessment of intestinal drug absorption, Eur. J. Pharm. Biopharm. 87 (2014) 227-235.

[124]

A.W. Larhed, P. Artursson, E. Bjork, The influence of intestinal mucus components on the diffusion of drugs, Pharm. Res. 15 (1998) 66-71.

[125]

B.T. Burruano, R.L. Schnaare, D. Malamud, Synthetic cervical mucus formulation, Contraception 66 (2002) 137-140.

[126]

M. Dawson, E. Krauland, D. Wirtz, J. Hanes, Transport of polymeric nanoparticle gene carriers in gastric mucus, Biotechnol. Prog. 20 (2004) 851-857.

[127]

M.R.C. Marques, R. Loebenberg, M. Almukainzi, Simulated biological fluids with possible application in dissolution testing, Dissolut. Technol. 18 (2011) $15-28$.

[128]

N. Navabi, M.A. McGuckin, S.K. Linden, Gastrointestinal cell lines form polarized epithelia with an adherent mucus layer when cultured in semi-wet interfaces with mechanical stimulation, PLoS One 8 (2013), e68761.

[129]

M.E. Diebel, L.N. Diebel, C.W. Manke, D.M. Liberati, Estrogen modulates intestinal mucus physiochemical properties and protects against oxidant injury, J. Trauma Acute Care Surg. 78 (2015) 94-99.

[130]

M. Boegh, H.M. Nielsen, Mucus as a barrier to drug delivery - understanding and mimicking the barrier properties, Basic Clin. Pharmacol. Toxicol. 116 (2015) 179-186

[131]

I. Lozoya-Agullo, F. Araujo, I. González-Álvarez, M. Merino-Sanjuán, M. González-Álvarez, M. Bermejo, B. Sarmento, Usefulness of Caco-2/ HT29-MTX and Caco-2/HT29-MTX/Raji B coculture models to predict intestinal and colonic permeability compared to Caco- 2 monoculture, Mol. Pharm. 14 (2017) 1264-1270.

$[132]$

R.A. Cone, Mucus, in: J. Mestecky, M.E. Lamm, W. Strober, J. Bienenstock, J.R. McGhee, L. Mayer (Eds.), Mucosal Immunol, Academic Press, San Diego, CA, USA, 2005, pp. 49-72.
[133]

J. Kočevar-Nared, J. Kristl, J. Šmid-Korbar, Comparative rheological investigation of crude gastric mucin and natural gastric mucus, Biomaterials 18 (1997) $677-681$

[134]

T. Sandberg, H. Blom, K.D. Caldwell, Potential use of mucins as biomaterial coatings. I. Fractionation, characterization, and model adsorption of bovine, porcine, and human mucins, J. Biomed. Mater. Res. A 91 (2009) 762-772.

[135]

V.J. Schömig, B.T. Käsdorf, C. Scholz, K. Bidmon, O. Lieleg, S. Berensmeier, An optimized purification process for porcine gastric mucin with preservation of its native functional properties, RSC Adv. 6 (2016) $44932-44943$.

$[136]$

A.W. Larhed, P. Artursson, J. Grasjo, E. Bjork, Diffusion of drugs in native and purified gastrointestinal mucus, J. Pharm. Sci. 86 (1997) 660-665.

[137]

J.S. Crater, R.L. Carrier, Barrier properties of gastrointestinal mucus to nanoparticle transport, Macromol. Biosci. 10 (2010) 1473-1483.

[138]

O. Lieleg, C. Lieleg, J. Bloom, C.B. Buck, K. Ribbeck, Mucin biopolymers as broad-spectrum antiviral agents, Biomacromolecules 13 (2012) 1724-1732.

[139]

B.J. Teubl, M. Absenger, E. Fröhlich, G. Leitinger, A. Zimmer, E. Roblegg, The oral cavity as a biological barrier system: design of an advanced buccal in vitro permeability model, Eur. J. Pharm. Biopharm. 84 (2013) 386-393.

$[140]$

S.A. Shukair, S.A. Allen, G.C. Cianci, D.J. Stieh, M.R. Anderson, S.M. Baig, C.J. Gioia, E.J. Spongberg, S.M. Kauffman, M.D. McRaven, H.Y. Lakougna, C. Hammond, P.F. Kiser, T.J. Hope, Human cervicovaginal mucus contains an activity that hinders HIV-1 movement, Mucosal Immunol. 6 (2013) 427-434.

$[141]$

S.K. Lai, K. Hida, S. Shukair, Y.Y. Wang, A. Figueiredo, R. Cone, T.J. Hope, J. Hanes, Human immunodeficiency virus type 1 is trapped by acidic but not by neutralized human cervicovaginal mucus, J. Virol. 83 (2009) 11196-11200.

[142]

J. das Neves, R. Nunes, F. Rodrigues, B. Sarmento, Nanomedicine in the development of anti-HIV microbicides, Adv. Drug Deliv. Rev. 103 (2016) 57-75.

[143]

J. das Neves, B. Sarmento, Precise engineering of dapivirine-loaded nanoparticles for the development of anti-HIV vaginal microbicides, Acta Biomater. 18 (2015) 77-87

[144]

D. Vllasaliu, L. Casettari, R. Fowler, R. Exposito-Harris, M. Garnett, L. Illum, S. Stolnik, Absorption-promoting effects of chitosan in airway and intestinal cell lines: a comparative study, Int. J. Pharm. 430 (2012) 151-160.

[145]

A. Wikman, P. Artursson, E. Btork, The influence of intestinal mucus components on the diffusion of drugs, Pharm. Res. 15 (1998) 66-71.

[146]

A. Wikman, J. Karlsson, I. Calstedt, P. Artursson, A drug absorption model based on the mucus layer producing human intestinal goblet cell line HT29-H, Pharm. Res. 10 (1993) 843-852.

[147]

A. Lechanteur, A. Almeida, B. Sarmento, Elucidation of the impact of cell culture conditions of Caco-2 cell monolayer on barrier integrity and intestinal permeability, Eur. J. Pharm. Sci. (2017), (in press).

[148]

C. Kitson, J.B. Angel, D. Judd, S. Rothery, N. Severs, A. Dewar, L. Huang, S. Wadsworth, S. Cheng, D. Geddes, E. Alton, The extra- and intracellular barriers to lipid and adenovirus-mediated pulmonary gene transfer in native sheep airway epithelium, Gene Ther. 6 (1999) 534-546. 